\title{
Evidence for silencing compartments within the yeast nucleus: a role for telomere proximity and Sir protein concentration in silencer-mediated repression
}

\author{
Laurent Maillet, ${ }^{1}$ Cécile Boscheron, ${ }^{1}$ Monica Gotta, ${ }^{2}$ Stéphane Marcand, ${ }^{1}$ Eric Gilson,,${ }^{1,3}$ \\ and Susan M. Gasser ${ }^{2}$ \\ ${ }^{1}$ Laboratoire de Biologie Moléculaire et Cellulaire de l'Ecole Normale Supérieure de Lyon UMR49, Centre National de la \\ Recherche Scientifique (CNRS)/Ecole Normale Supérieure (ENS), F-69364 Lyon CEDEX 07, France; ${ }^{2}$ Swiss Institute for \\ Experimental Cancer Research (ISREC), CH-1066 Epalinges s/Lausanne, Switzerland
}

Transcriptional repression at the silent mating-type loci in yeast requires the targeting of silent information regulator (Sir) proteins through specific interactions formed at cis-acting silencer elements. We show here that a reporter gene flanked by two functional silencers is not repressed when integrated at $>200 \mathrm{~kb}$ from a telomere. Repression is restored by creation of a new telomere $13 \mathrm{~kb}$ from the integrated reporter or by elevated expression of SIR1, SIR3, and/or SIR4. Coupled expression represses in an additive manner, suggesting that all three factors are in limiting concentrations. When overexpressed, Sir3 and Sir4 are dispersed throughout the nucleoplasm, in contrast to wild-type cells where they are clustered in a limited number of foci together with telomeres. Efficient silencer function thus seems to require either proximity to a pool of concentrated Sir proteins, that is, proximity to telomeres, or delocalization of the silencing factors.

[Key Words: Silencing; SIR; yeast mating type; telomere position effect; subnuclear organization]

Received April 11, 1996; revised version accepted May 29, 1996.

The organization of eukaryotic DNA within the interphase nucleus must facilitate the maintenance, replication, recombination, and coordinated expression of the genetic material. Several lines of evidence suggest that chromosomal domains are organized within the interphase nucleus. First, in situ hybridization with whole chromosome probes has demonstrated that mammalian chromosomes occupy specific territories and are not intertwined in the nucleoplasm (Cremer et al. 1993). Second, specific domains, such as telomeres and centromeres, often show nonrandom subnuclear distribution. For instance, telomeres appear to be adjacent to the nuclear envelope in polytene nuclei and embryonic cells of Drosophila (Mathog et al. 1984) and appear clustered in foci in budding yeast (Klein et al. 1992; Palladino et al. 1993; Cockell et al. 1995; Gotta et al. 1996 I. In fission yeast and in mammalian tissue culture cells, cell cycledependent positioning of telomeres has been observed (Funabiki et al. 1993; Vourc'h et al. 1993) and most species show a clustering of telomeres at the nuclear enve-

${ }^{3}$ Corresponding author. lope in the "bouquet" stage of meiosis (for review, see Gilson et al. 1993).

In several instances the subnuclear localization of a chromosome or a chromosomal domain could be closely correlated with its transcriptional state. For instance, it has been observed that electron-dense, negatively stained heterochromatin remains highly condensed and localized at the nuclear periphery in differentiated interphase cells (e.g., see Rae and Franke 1972; Mathog et al. 1984 ), as is the inactive X chromosome of mammalian females (Walker et al. 1991). In addition, the inactive, centromeric heterochromatin of Drosophila salivary gland nuclei coalesces into a single chromocenter (Heitz 1934). In brief, a variety of long-range interactions between chromosomal regions can be detected, which may also involve interactions between chromatin and elements of nuclear substructure. However, despite extensive correlations, the functional relationships between subnuclear organization and mechanisms that regulate gene expression remain unknown.

Local chromatin organization, usually envisaged as domain structure or as a conformation propagated along the nucleosomal fiber, is also responsible for the activation and inactivation of genes. In flies this is true for 
certain developmental programs of gene expression (Paro 1993), for centromeric position-effect variegation (for review, see Karpen 1994), and it is reflected in the variable expression of foreign genes integrated into mammalian chromosomes (e.g., Butner and Lo 1986). In the yeast Saccharomyces cerevisiae, gene repression at the silent mating-type loci $(H M L$ and $H M R$, collectively termed the $H M$ loci) correlates with a general reduction in accessibility of the repressed domain to the yeast endonuclease $\mathrm{HO}$ and other DNA modifying enzymes (for review, see Laurenson and Rine 1992). In a similar fashion, polymerase II genes positioned adjacent to the poly $\left(\mathrm{TG}_{1-}\right.$ 3) tracts at yeast telomeres were found to succumb to a heritable but reversible transcriptional inactivation (Gottschling et al. 1990), which appears to spread inward from the telomere (Renauld et al. 1993).

The nucleation of the repressed chromatin state at telomeres requires a cis-acting DNA element, the telomeric $\mathrm{TG}_{1-3}$ repeat, to which bind multiple copies of repressor activator protein 1 (Rap1; Gottschling et al. 1990; Liu et al. 1994; Stavenhagen and Zakian 1994; Buck and Shore 1995). At HML and HMR, short cis-acting silencer elements serve the same purpose, and, like enhancers, these silencers function at variable distances to repress targeted promoters (Brand et al. 1985, 1987; Mahoney and Broach 1989). Motifs within the cis-acting silencers (called $\mathbf{E}$ or $\mathbf{I}$ ) are again recognized by transacting factors needed for the establishment of silencing, namely Rapl (Shore and Nasmyth 1987), Abfl (ARS binding factor 1; Buchman et al. 1988), and the origin recognition complex (ORC; Micklem et al. 1993), a sixpolypeptide complex that recognizes the ARS consensus (Bell et al. 1993).

Sites for any two of the three silencer binding factors are sufficient for silencer function, at least in the context of the HM loci where a second partially functional silencer is present (i.e., HMR-I or HML-I; Brand et al. 1985, 1987; McNally and Rine 1991; Boscheron et al. 1996), and genetic results show that silencing at $H M$ loci and telomeres requires the carboxy-terminal 130 amino acids of Rap1 (Sussel and Shore 1991; Kyrion et al. 1993; Liu et al. 1994). When long stretches of the $\left(\mathrm{TG}_{1-3}\right)_{n}$ telomeric repeat are integrated within the genome, they also confer a Sir-dependent repression of adjacent promoters (Stavenhagen and Zakian 1994), although a minimum of 828 bp (containing $>40$ potential Rap1-binding sites) are required. The fact that $H M$ silencers repress genes more efficiently than internal telomeric tracts is thought to reflect the juxtaposition of Rapl to ORC and Abfl sites but may also reflect the chromosomal context of $H M$ loci (see below).

In addition to the cis-acting sequences and their ligands, both telomeric and mating-type silencing require the silent information regulator genes, SIR2, SIR3, and SIR4, the NAT1/ARD1 amino-terminal acetylase, and the amino termini of histones $\mathrm{H} 3$ and $\mathrm{H} 4$ (for review, see Laurenson and Rine 1992). Differences in the mechanisms of $H M$ and telomeric silencing have also been noted. Namely, sir1 mutations weaken silencing at $H M L$, rendering it metastable (Pillus and Rine 1989), al- though it has no effect at telomeres (Aparicio et al. 1991). Nonetheless, an artificially targeted Sirl can enhance telomere-proximal silencing (Chien et al. 1993). Conversely, overexpression of the TLC1 gene, encoding the RNA component of telomerase, derepresses at telomeres but has little effect on HM loci (Singer and Gottschling 1994).

Several lines of evidence suggest that Sir3 and Sir4 are structural components of repressed chromatin. First, they were shown to bind the amino termini of histones $\mathrm{H} 3$ and H4 in vitro (Hecht et al. 1995). Furthermore, deletions that derepress silencing in vivo both disrupt the in vitro binding and result in an altered localization of Sir3 and Sir4 in yeast nuclei, suggesting direct interactions with nucleosomes in vivo (Hecht et al. 1995). Second, overexpression of Sir4 or the carboxy-terminal domain of Sir4 derepresses both mating-type and telomeric silencing (Marshall et al. 1987; Cockell et al. 1995), whereas overexpression of Sir3 extends repression inwards from a marked telomere (Renauld et al. 1993). Third, Sir3 and Sir4 interact in two-hybrid assays with themselves, with each other, and with Rapl (Chien et al. 1991; Moretti et al. 1994), and Sir4 and Rapl coprecipitate in a DNase-insensitive complex from yeast nuclear extracts (Cockell et al. 1995). Finally, Rapl, Sir3, and Sir4 proteins all localize by immunofluorescence to a limited number of foci, many of which appear to be near the nuclear periphery (Palladino et al. 1993). Recently, combined immunofluorescence and in situ hybridization studies have shown that Rap1, Sir3, and Sir4 immunofluorescence signals coincide with hybridization signals of subtelomeric repeats (Gotta et al. 1996). The correlation of repression with the concentration of Rapl and Sir3 in foci have led to the hypothesis that transcriptional silencing may be facilitated by the juxtaposition of telomeres with each other and/or with the nuclear envelope (Palladino and Gasser 1994; Hecht et al. 1995), although such clustering is clearly not sufficient for the establishment or maintenance of repression (Cockell et al. 1995).

The presence of the silent mating-type loci near the telomeres of chromosome III $\sim \sim 13 \mathrm{~kb}$ for $H M L$ and $25 \mathrm{~kb}$ for $H M R$ / has led to the speculation that this particular chromosomal location of these loci may also contribute to the HM silencing process (Gilson et al. 1993). Indeed, moving the HM loci away from the telomere was shown to affect their silencing properties (Thompson et al. 1994; Shei and Broach 1995). Here, we further investigate the role of chromosomal context in silencing by integrating a reporter gene flanked by complete $H M L-E$ and $H M L-I$ silencers to quantify repression at various chromosomal sites. We demonstrate that proximity to telomeric repeat sequence is necessary for the repression of our reporter construct, although this requirement can be overcome by an elevated expression of Sir1, Sir3, and Sir4 proteins. These factors are thus limiting for some sites in the chromosome but not for others, suggesting the existence of concentration gradients or pools of silencing factors within the wild-type yeast nucleus. We speculate that this unequal distribution of Sir proteins 
essentially creates compartments within the nucleus that can influence the function of Rapl and Abfl as either activators or repressors of transcription.

\section{Results}

HML silencer-mediated repression is dependent on chromosomal location

We have established a rapid, quantitative assay for silencer- and Sir-mediated gene repression in yeast, based on a reporter construct in which the $\alpha 1$ and $\alpha 2$ coding regions at $H M L$ are replaced by a minimal $L E U 2$ promoter fused to the bacterial lacZ gene (the LEU2' 'lacZ gene). This construct is flanked by $>1 \mathrm{~kb}$ of sequence from each side of the $H M L$ locus, including the $\mathbf{E}$ and the I silencer elements (the $\mathbf{E}>\mathbf{I}$ construct in Fig. 1A). When integrated into the genome, this construct allows us to monitor silencing quantitatively using a soluble assay for $\beta$-galactosidase. We have demonstrated previously that cells carrying the $L E U 2^{\prime \prime} l a c Z$ integrated at the $H M L$ locus have very low $\beta$-galactosidase activity $(0.07$ Miller unit, standardized as 1 ; see Fig. 1B, strain EG5; Boscheron et al. 1996). Expression levels increase by $40-$ to 60 -fold in the absence of silencers or in strains lacking sir1 or sir3, and, like natural HM silencing, it is independent of the promoter orientation with respect to the silencers (Boscheron et al. 1996). Because inactivation of Sir3 or Sir4 results in the complete derepression of $H M L \alpha$ and HMRa (Klar et al. 1981; Nasmyth et al. 1981; Ivy et al. 1986), we assume that the $\beta$-galactosidase activity measured in sir 3 or sir 4 cells corresponds to the fully derepressed level of the reporter cassette.

To examine whether $H M$ silencing is influenced by its natural chromosomal location near the left end of chromosome III, we inserted the $L E U 2^{\prime}$ 'lacZ gene flanked by the two functional $H M L$ silencers at four internal chromosomal loci: within the LYS2 gene, located $342 \mathrm{~kb}$ from the right end of chromosome $\mathrm{II}_{\text {; }}$ adjacent to the HIS3 gene, $\sim 250 \mathrm{~kb}$ away from the right telomere of chromosome XV; downstream of the KEX2 gene, $\sim 200$ $\mathrm{kb}$ away from the left telomere of chromosome XIV; and downstream of the SIN4 gene, at $\sim 5 \mathrm{~kb}$ centromere proximal from the KEX2 insertion. In all cases the recipient chromosomes are significantly larger than chromosome III. The insertional events were confirmed by both PCR and Southern blot restriction site analysis (Materials and methods; data not shown).

The expression level of the $L E U 2^{\prime \prime} l a c Z$ gene flanked by two functional silencers (the $\mathbf{E}>\mathbf{I}$ construct in Fig. 1A) increases 40- to 43-fold when inserted at LYS2, HIS3, $K E X 2$, or at SIN4, as compared with insertion at $H M L$ (cf. Fig. 1B, strains EG5, EG59, EG112, LM2, and LM3). All values for $\beta$-galactosidase activity are standardized to the expression level of the same construct inserted at $H M L$. Deletion of the $\mathbf{E}$ silencer at $L Y S 2$ (the $\mathbf{e}_{\mathbf{1}}>\mathbf{I}$ construct in Fig. 1A and strain EG36 in Fig. 1B) results in a fully derepressed level of the reporter gene expression because the $\beta$-galactosidase activity is equivalent to that ob-
$\mathbf{A}$

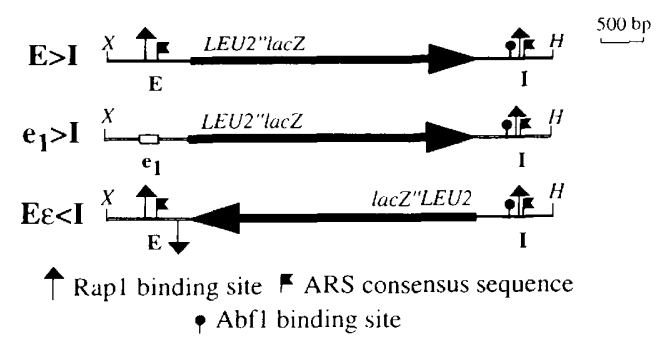

B

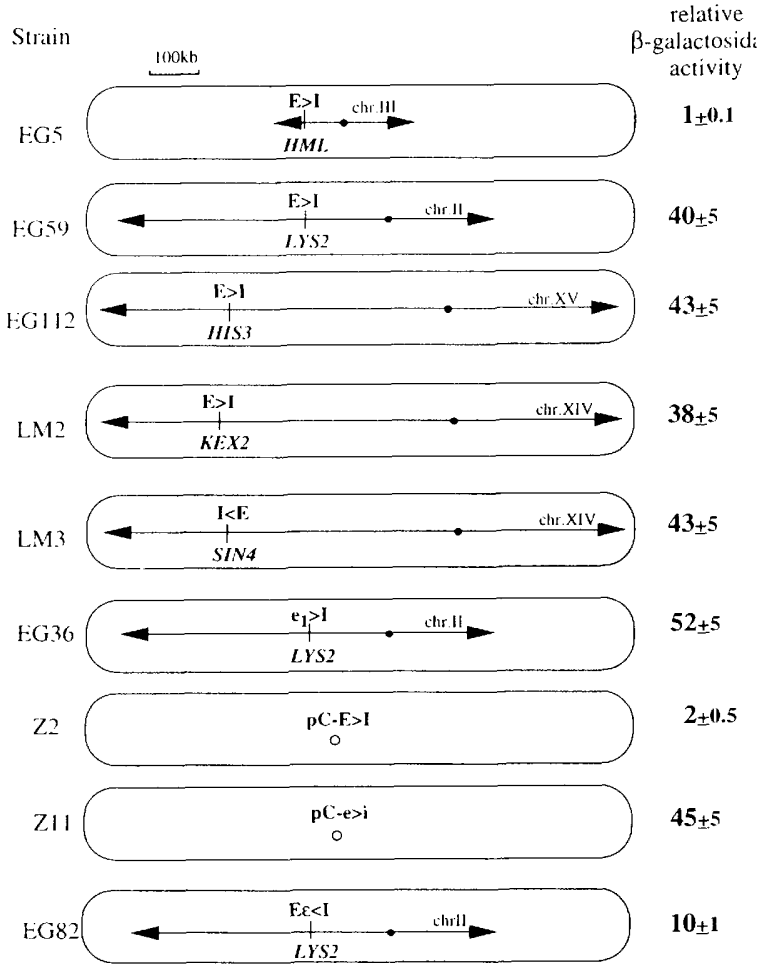

Figure 1. The chromosomal context influences the expression of a $L E U 2^{\prime \prime} l a c Z$ reporter flanked by $H M L-E$ and $H M L-I .|A| \mathrm{Di}$ agram of the $L E U 2^{\prime \prime} l a c Z$ silencing cassettes. The 3.4-kb $L E U 2^{\prime \prime} I a c Z$ reporter gene is expressed under the control of a minimal LEU2 promoter. The symbols representing the mapped Rapl, Abfl, and ARS consensus sequences (ACS) are shown at the bottom. E $>\mathbf{I}$ indicates that both $\mathbf{E}$ and $\mathbf{I}$ silencers are present and that the promoter of the reporter gene is located near $\mathbf{E}, \mathbf{e}_{\mathbf{1}}>\mathbf{I}$ is deleted for $\mathbf{E}$ and $\mathbf{E} \boldsymbol{\epsilon}<\mathbf{I}$ includes a RAPl-binding site in between $\mathbf{E}$ and the $3^{\prime}$ end of the reporter gene. $(X) X b a I_{i}$ $(H)$ HindIII. $(B)$ The relative $\beta$-galactosidase activities produced in yeast strains carrying the indicated $L E U 2^{\prime \prime} l a c Z$ silencing cassettes are given to the right of the strain tested. All strains are isogenic except for the integration or plasmid indicated in the oblong circles, and all carry a $L E U 2$-expressing vector. The standard deviation of the mean was calculated from the results of at least four independent trials using two parallel reactions for each point; the standard deviation is indicated. The strain EG5 carries the E $>\mathbf{I}$ cassette at $H M L$ and produces 0.07 Miller unit (Boscheron et al. 1996) that was standardized to 1. Arrows represent telomeres and dots indicate the position of the centromere. The position of the targetted silencing cassette is shown by a vertical bar. Replicative plasmids ( $\mathrm{pC}-\mathrm{E}>\mathrm{I}$ and $\mathrm{pC}-\mathrm{e}>\mathrm{i})$ are represented $(\mathrm{O})$. 
served for the construct at $H M L$ in cells mutant for sir1, sir3, or sir4 (Fig. 2A, columns 2-4). The expression of the reporter gene at LYS2 is only slightly increased by $\mathrm{mu}-$ tations in the SIR genes (Fig. 2B, columns 2-4) or by overexpression of the Sir4 carboxy-terminal domain (data not shown), which fully derepresses the $\mathbf{E}>\mathbf{I}$ construct integrated at HML (Boscheron et al. 1996). These results suggest that $H M L$ silencer function depends at

A
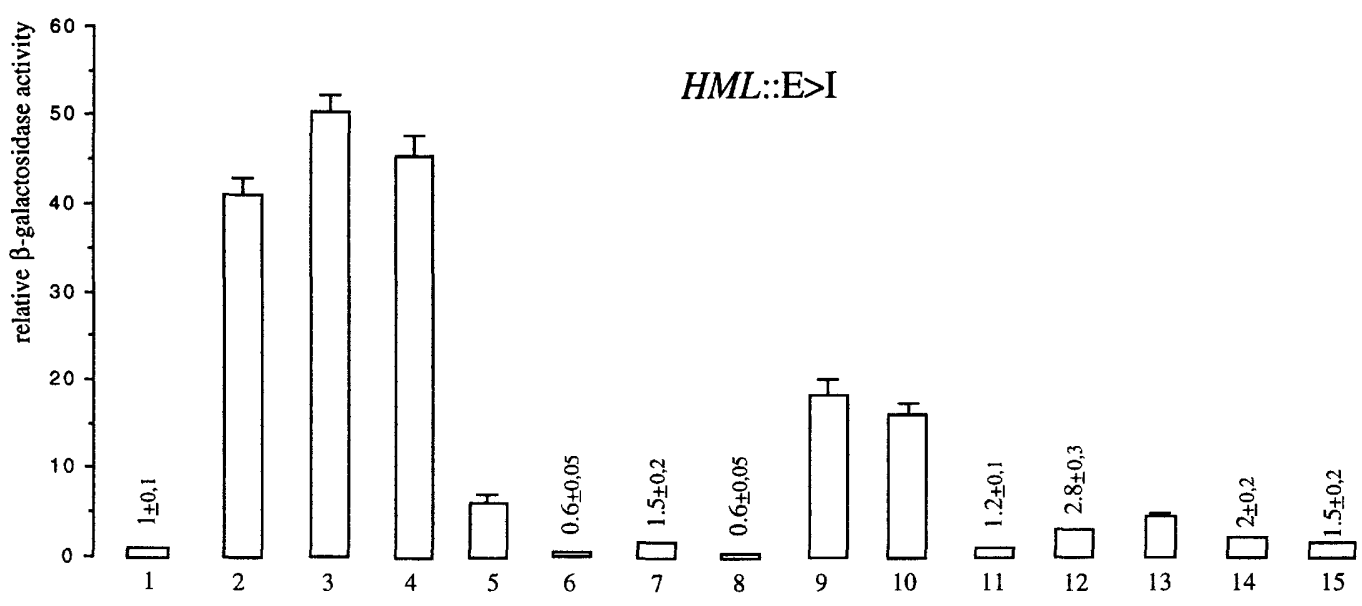

B

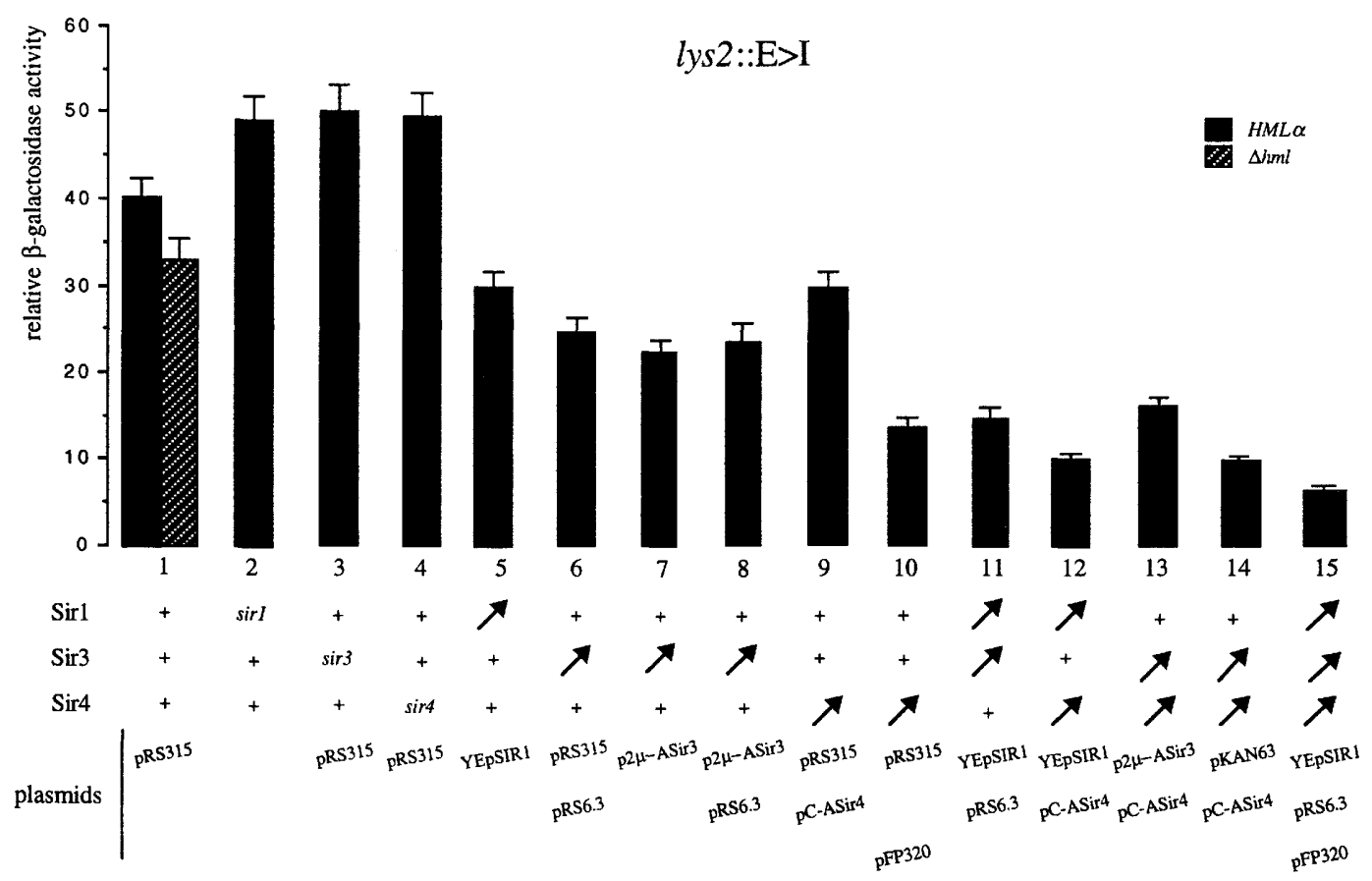

Figure 2. Silencer-mediated repression at the LYS2 locus requires elevated concentrations of Sir proteins. The dependence of the LEU2' 'lacZ expression on silencing factors is illustrated in EG37 (hml::E $>\mathrm{I} ; A)$ and EG70 $(l y s 2:: \mathrm{E}>\mathrm{I} ; B)$ by the disruption of $\operatorname{sir} 1$ by LEU2, sir3 by TRP1, and sir4 by HIS 3 (columns 2, 3, and 4, respectively) or by transforming with plasmids overexpressing the genes encoding Sir1 (YEpSIR1) or Sir3 (pKAN63, p2 $\mu$-ASir3, pRS6.3) or Sir4 (pC-ASir4, pFP320). All the cells contain a functional LEU2 gene either in the chromosome (sir1::LEU2) or on a plasmid (pRS315, YEpSIR1, p2 $\mu$-ASir3, or pKAN63) to allow growth in media selective for leucine. The sir disruptions and plasmids are listed below the columns and are applicable to both $A$ and $B$. Plasmids in the top row all carry LEU2 and in the middle carry URA3, and pFP320 carries TRP1. When two or three plasmids were carried by the same strain, they are listed vertically. All measurements were made on media selective for leucine and, when necessary, for tryptophan and/or uracil. EG37 and EG70 carrying any combination of one, two, or three of the following parental plasmids without SIR gene inserts produced similar amounts of $\beta$-galactosidase: pRS315 (CEN-ARS LEU2), pAAH5 (2 $\mu-L E U 2)$, pRS314 (CEN-ARS TRP1), pRS316 (CEN-ARS URA3). The comparison of $\beta$-galactosidase activities from $L E U 2^{\prime \prime}$ 'lacZ reporter at $L Y S 2$ (EG59) in the presence and absence of an intact $H M L$ locus is shown by the solid and hatched bars in column 1, respectively. In all cases the activity is presented relative to that obtained with EG5 carrying pRS315 (A, column 1, 0.07 Miller unit standardized to 1). The error bars represent the standard deviation of the mean. Very low values from the insert at $H M L$ are indicated above the bars. 
least partially on chromosomal context; that is, constructs that repress at $H M L$ do not necessarily do so at internal loci.

To verify that the translocated fragment of $H M L$ is indeed sufficient to confer silencing, the HML::LEU2" lacZ DNA (i.e., E $>\mathbf{I}$ ) that was inserted at internal locations was cloned on a CEN-containing plasmid. The expression of the reporter gene is now repressed by the flanking silencer sequences, as observed at their native location at $H M L$ (strain Z2; Fig. 1B). Again, repression is fully dependent on intact silencer sequences, and the expression level of the plasmid-borne construct without silencers is equivalent to the intact construct inserted at internal loci (strain Z11, Fig. 1B). This shows that all the genetic information necessary for silencing is contained within the $H M L$ DNA fragments inserted at LYS2, HIS3, KEX2, and SIN4. Moreover, this result suggests that the factors or conditions that restrict repression at internal loci are not applicable to a plasmid-borne construct.

To exclude that the absence of silencer-mediated repression at $L Y S 2$ is a peculiarity of the $L E U 2^{\prime \prime} l a c Z$ reporter, we have inserted the URA3 or the $A D E 2$ gene flanked by $H M L$ silencers at various loci. When integrated at $H M L$, variegated expression of URA3 was visualized by the growth of $\sim 10 \%$ of the plated cells on 5-fluoro-orotic acid (5-FOA) and by sectored pink/red colonies for the $A D E 2$ construct (data not shown). In contrast, no repression was monitored when either construct was integrated at LYS2 (data not shown). This position-dependent silencer function is not strain specific, because the insertion of the same URA3 silencing construct at $H M L$ or at $L Y S 2$ in a diploid strain of a different parental background shows repression at $H M L$ but not at LYS2 (data not shown). Interestingly, when integrated at the SUC2 locus found at $\sim 25 \mathrm{~kb}$ from the left end of chromosome IX (Carlson et al. 1985), the URA3 silencing construct is repressed to a level similar to that observed at the natural HML locus (data not shown). Although this repression might reflect the late timing of replication that characterizes telomere-proximal sequences (Ferguson and Fangman 1992), we were unable to measure repression when the silencer-flanked reporter was integrated at KEX2 and SIN4, two internal locations reported to be late replicating (Fig.1B; cited in Diller and Raghuraman 1994). These results suggest that proximity to a telomere, not simply sequence context, influences silencer-mediated repression.

\section{The formation of a new telomere in cis restores HML silencer function at LYS2}

To test whether telomere proximity can improve silencer function at $L Y S 2$, we have fragmented the distal part of the chromosome that carries the HML::LEU2"lacZ DNA at $L Y S 2$ in a diploid strain (Fig. 3A). In diploid cells, the HML::LEU2' 'lacZ construct inserted at LYS2 is derepressed, with a level of $\beta$-galactosidase 43 -fold higher than that measured when the same construct is inserted at $H M L$ (Fig. 3B, cf. EG84 and EG85). Truncating chromosome II places the reporter construct $13 \mathrm{~kb}$ from the newly formed telomere and results in full repression of the reporter gene (Fig. 3B, cf. EG84 and EG86). To demonstrate that this is not owing to a reduction in the dosage of a gene carried on the distal arm of chromosome II, we have performed a similar truncation on the chromosome II homolog lacking the reporter construct. In this case no repression is observed (Fig. 3B, strain EG87), demonstrating that it is formation of a new telomere in cis that influences silencer function at LYS2. This also confirms that no sequence within the $13 \mathrm{~kb}$ distal of LYS2 inherently interferes with silencing. Thus, we conclude that the lack of silencer-mediated repression at LYS2 in its normal chromosomal position probably reflects the large distance that separates this locus from its most proximal telomere.

\section{Internal silencing is not attributable to propagation from the proximal telomere}

We observe that the HML::LEU2" 'lacZ is efficiently repressed when positioned within $13 \mathrm{~kb}$ of a telomere (i.e., at $H M L$ or near a fragmented end of chromosome II). It is conceivable that this organization allows the linear propagation of telomeric silencing from the end of the chromosome to the reporter construct, rather than promoting the de novo establishment of repression by the adjacent silencers. To test this we inserted the URA3 gene $3.1 \mathrm{~kb}$ away from the $\mathrm{TG}_{1-3}$ repeats at the left telomere of chromosome III in a strain carrying $L E U 2^{\prime \prime} l a c Z$ at $H M L$ (strain EG47; Fig. 4). Under these conditions URA3 exhibits the expected variegated pattern of expression, producing $\sim 5 \% 5-$ FOA $^{\mathrm{R}}$ colonies (data not shown). By growing these strains in the presence of 5-FOA or in the absence of uracil we place a continual selection on the cells for either the repression of $U R A 3$ or its transcription at a level sufficient to support uracil biosynthesis. By comparing the two conditions of growth, we can monitor expression of the HML::LEU2' lacZ construct in relation to the repressed or active state of the telomere-proximal URA3.

During 10 generations of growth on either 5-FOA or uracil-deficient media, the expression of the LEU2' 'lacZ gene flanked by both $\mathbf{E}$ and $\mathbf{I}$ at $H M L$ is unchanged, remaining at a fully repressed level (strain EG47; Fig. 4). This stable, repressed level of $H M L:: L E U 2^{\prime \prime} l a c Z$ expression is also observed when URA3 is inserted at the telomere of another chromosome, allowing us to conclude that neither growth conditions nor the transcriptional state of a telomere-proximal $U R A 3$ has an effect on expression at $H M L$ (strain EG93; Fig. 4). We were able to extend this analysis to the $H M L:: L E U 2^{\prime \prime}$ lacZ reporter inserted at LYS2, because the insertion of the telomeric repeat $13 \mathrm{~kb}$ away from LYS2 coincided with the integration of an intact $U R A 3$ gene immediately adjacent to the telomere. Again, the tight repression of the $H M L:: L E U 2^{\prime \prime} l a c Z$ reporter is shown to be independent of the transcriptional state of URA3 modulated by growth on either uracil-deficient or 5-FOA media (strain EG86; Fig. 4). This indicates that silencer-mediated repression at $H M L$ and at other internal sites is indepen- 


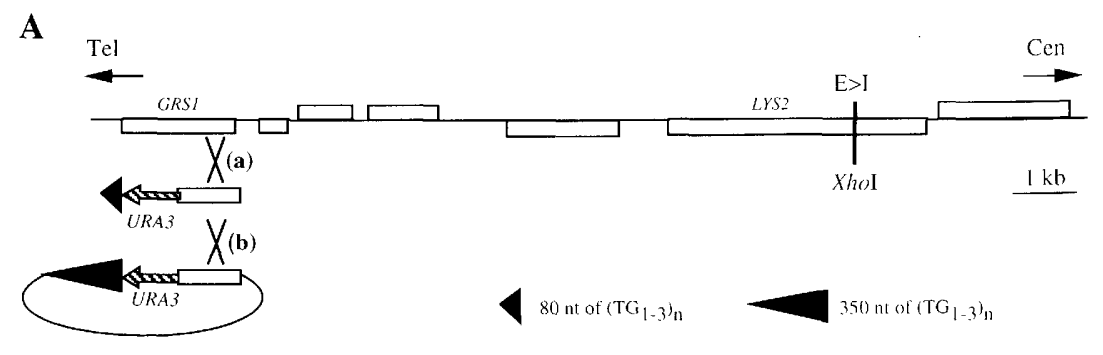

B
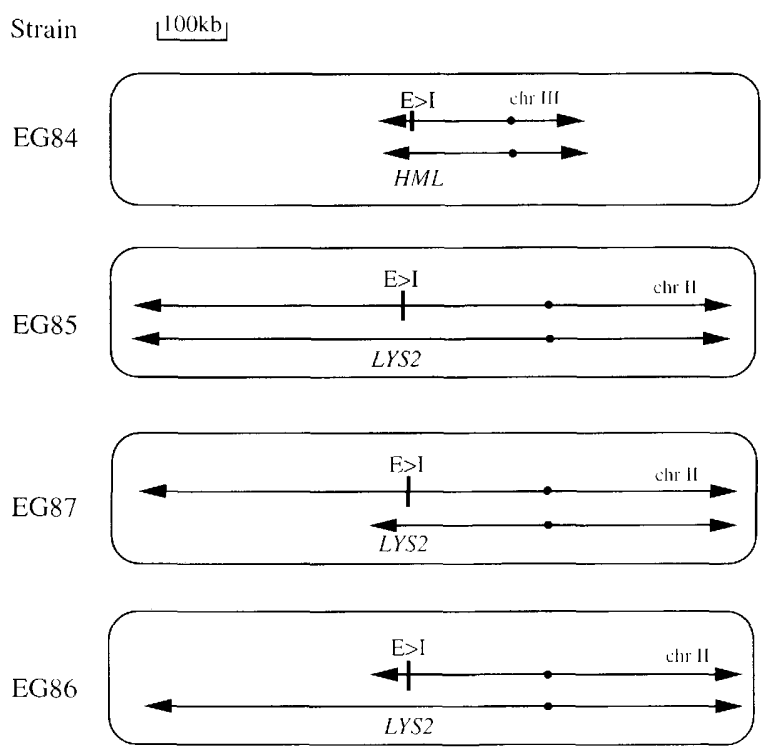

LMI

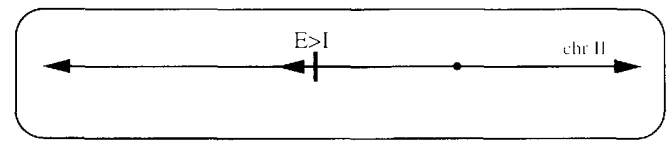

relative $\beta$-galactosidase activity

$1 \pm 0.2$

$43 \pm 5$ $55 \pm 7$ $1+0.2$ $1 \pm 0.3$
Figure 3. Insertion of yeast telomeric repeats $13 \mathrm{~kb}$ from $L Y S 2$ restores repression. (A) The integration of yeast telomeric repeats at the GRS1 locus on chromosome II is depicted on the genetic map of the GRS1-LYS2 region. Hanging rectangles are ORFs transcribed toward the centromere, and upright rectangles are those transcribed toward the telomere. The site of integration of the $\mathbf{E}>\mathbf{I}$ silencing cassette at LYS2 is represented by a vertical bar. $\mathrm{X}$ indicates the site of integration in GRS1 of either (a) a linear DNA fragment derived from pURATel80LYS exposing at one end 80 nucleotides of $\left(\mathrm{TG}_{1-3}\right)_{n} \mathrm{DNA}$ or $(\mathbf{b})$ the plasmid pURATel350LYS cut at a unique site within the GRS1 region, which inserts 350 nucleotides of $\left(\mathrm{TG}_{1-3}\right)_{n}$ without creating a telomeric end. Integration a was done in the diploid strain EG85 and Southern blots were done to confirm whether the integration was in the lys2::LEU2" 'lacZ marked chromosome (creating EG86) or in the other homolog (creating EG87). Integration b was done in the haploid strain EG59 creating strain LM1. (B) The diploids EG84 and EG85 are described in Materials and methods, and EG87, EG86, and LM1 are described in $A$. $\beta$-Galactosidase activity and calculation of relative activity is as described in Fig.1. dent of the state of expression at the immediately proximal telomere, even though proximity to a telomeric repeat does facilitate the establishment of repression. The independence of these two related silencing events is underscored by the fact that repression of the $H M L:: L E U 2^{\prime \prime} l a c Z$ reporter inserted at $H M L$ is derepressed in sir1 cells (Fig. 2A, column 2; Boscheron et al. 1996), whereas the telomeric silencing of the URA3 gene located in between the left telomere of chromosome III and $H M L$ is not (strain EG47; Fig. 4; data not shown).

\section{Additional Rap1 sites allow repression of HML::LEU2" lacZ at LYS2}

At $H M L$ the insertion of an additional Rap1-binding site $3^{\prime}$ of the reporter gene (the Rapl consensus from the $\alpha 2$ promoter) enhances the efficiency with which the double silencer construct represses $L E U 2^{\prime \prime} l a c Z$, although the binding site does not act as a silencer on its own /the $\mathrm{E} \epsilon<\mathrm{I}$ construct in Fig. 1A; see also Boscheron et al. 1996). We show here that it can also partially restore repression of the reporter gene at its internal LYS2 site (strain EG82;
Fig. 1B). Moreover, insertion of a series of Rapl sites, in the form of $350 \mathrm{bp}$ of $\mathrm{TG}_{1-3}$ repeat at a distance of $13 \mathrm{~kb}$ (Fig. $3 \mathrm{~A}$ ), also confers repression on the lys2::HML::LEU2' 'lacZ reporter, even without truncating the chromosome (Fig. 3B, strain LM1). By performing this insertion in a haploid cell, we ensure that the distal $342 \mathrm{~kb}$ of chromosome II, which encodes several essential genes, is not eliminated. Southern blot and PCR analyses confirm the location of the insertion and the lack of truncation (data not shown). We assume that the insertion of the $\mathrm{TG}_{1-3}$ sequence acts through the binding of Rap1, which has been shown by both molecular and immunological techniques to bind yeast telomeric repeats (for review, see Gilson and Gasser 1995). These observations suggest that a critical element provided by proximity to a telomere is an abundance of Rapl molecules and perhaps Rapl ligands.

\section{Overexpression of Sir1, Sir3, and Sir4 enables silencer-mediated repression at LYS2}

Why are internal chromosomal sites less conducive to silencer-mediated repression? Based on the unequal dis- 
Figure 4. Silencing is not propagated continuously from the telomere. The expression of the LEU2" lac $Z$ silencing cassette $(\mathbf{E}>\mathbf{I})$ is monitored either at the $H M L$ site of integration (EG93 and EG47) or at LYS2 (EG86). In all three strains the only wild-type URA3 allele is under the influence of TPE as follows: In EG93, the URA3 gene is integrated at a fragmented VIIL telomere and the silencing cassette is at $H M L$ on chromosome III. In EG47, the URA3 gene is located in between the telomere and HML::LEU2" lacZ on chromosome III, and similarly in EG86, the promoter of $U R A 3$ is at $1 \mathrm{~kb}$ from the telomeric repeat and $12 \mathrm{~kb}$ from the lys2::LEU2" lacZ reporter on chromosome II. As indicated at left, cells were grown in the absence or presence of uracil and in the

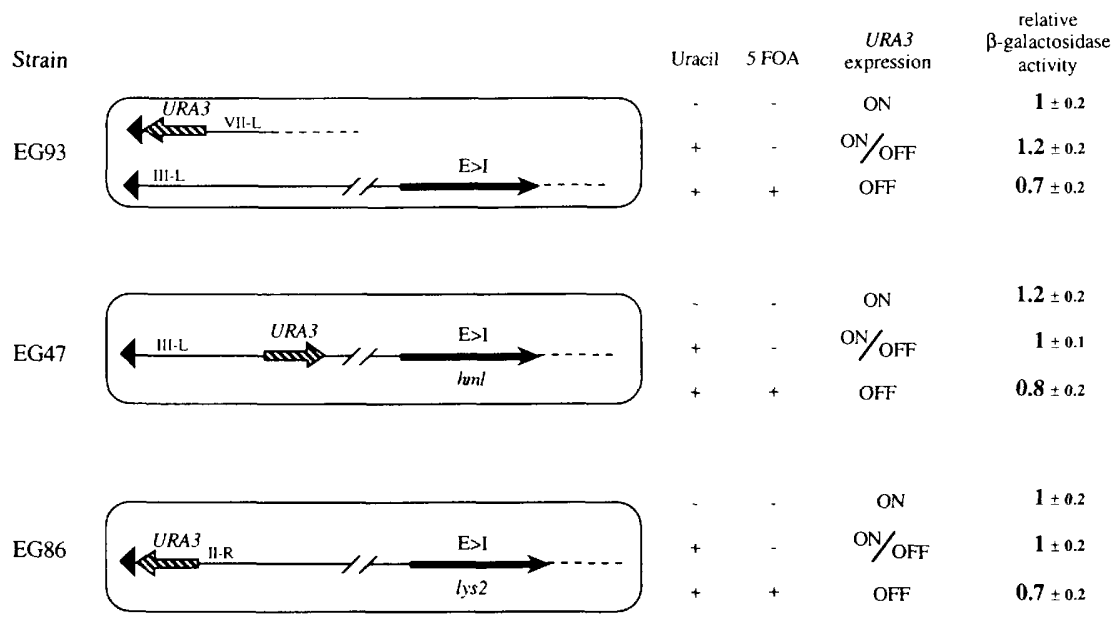
absence or presence of $1 \mathrm{mg} / \mathrm{ml}$ of 5-FOA, to select for cells that either express $(-$ uracil, ON $)$ or repress $(+5$-FOA, OFF) URA3. Cells grown with uracil but without 5-FOA are subject to variegated expression, which is indicated as ON/OFF. Cultures grew at least 10 generations before being assayed for $\beta$-galactosidase activity. The standard deviation of the mean was calculated on at least four independent trials and is presented as described in Fig. 1.

tribution of Rapl, Sir3, and Sir4 proteins in the nucleus (Klein et al. 1992; Palladino et al. 1993; Cockell et al. 1995), we speculated that internal chromosomal sites, like LYS2, may not have ready access to the high concentrations of Sir proteins found near telomeres. Consistent with this idea that Sir proteins are limiting, we see that a small degree of repression can be conferred on the reporter construct at $L Y S 2$, by deleting the $H M L$ locus in the control strain and thereby lowering the number of sites competing for Sir factors (Fig. 2B, column 1). To determine which Sir proteins might be limiting for silencer-mediated repression at $L Y S 2$, we transformed the strain carrying lys2::HML::LEU2' 'lacZ with plasmids expressing SIR gene products or with control vectors carrying only the selectable marker. In all cases the effects of SIR overexpression were also monitored in a fully isogenic strain carrying the $L E U 2^{\prime \prime} l a c Z$ reporter at $H M L$ instead of at LYS2. The levels and localization of the proteins were checked by immunoblotting (Fig. 5) and immunofluorescence (Fig. 6).

As described above, the $\beta$-galactosidase activity produced from the $L E U 2^{\prime \prime}$ lacZ construct integrated at LYS2 is $\sim 40$-fold higher than that detected from the same construct at $H M L$ (Fig. 2A,B, column 1). However, if Sir1 (Fig. 2B, column 5) or Sir3 (Fig. 2B, columns 6-8) or Sir4 (Fig. 2B, columns 9,10 ) are overproduced, a drop in the level of $\beta$-galactosidase is observed, reflecting a partial restoration of silencing at an internal location. These results suggest that these Sir proteins are limiting for repression at LYS2 or else that their overexpression alters the availability and/or the expression of other factors that are of limited supply. This last explanation was examined by Western blotting with affinity-purified monospecific antibodies, to determine the protein levels conferred by various SIR-expressing plasmids (Fig. 5). Within a twofold margin of error, Rapl levels remain constant in all cells tested (data not shown), whereas Sir3 and Sir4 levels increase between 8- and 50-fold upon transformation with plasmids overexpressing the appropriate gene (see legend to Fig. 5 for quantitation). The amount of Sir3 in the cell is largely unchanged by Sir4 overexpression and vice versa, indicating independent regulation of the two polypeptides. We are unable to monitor Sirl by Western blot but can nonetheless confirm that the introduction of YEpSIR1 does not significantly alter levels of Rap1 (data not shown), Sir3, or Sir4 (Fig. 5).

The Sir3 expression from a low-copy-number plasmid (pRS6.3) is sixfold lower than that from a multicopy plasmid carrying SIR3 under control of the ADC1 promoter (p2 $\mu$-ASir3; see Fig. 5), yet repression of the lys2::LEU2" 'lacZ reporter is approximately equal, even in the presence of both plasmids (Fig. 2B, column 8). Similarly, the partial repression brought about by roughly 30 -fold higher levels of Sir4 (pC-ASir4; Fig. 5) is not improved by further increasing SIR4 gene expression (data not shown). This suggests that Sir3 and Sir4 become saturating for internal silencing at sufficiently high dosage, further supporting the hypothesis that more than one silencing factor is limiting for internal silencing.

This hypothesis was tested directly by the pairwise introduction of constructs such that both Sirl and Sir3, both Sirl and Sir4, or both Sir3 and Sir4 or all three could be concomitantly expressed (Fig. 2B, columns 11-15). Under these conditions the enhanced repression conferred by the plasmid-borne genes is additive. Maximal repression is achieved in the presence of all three plasmids and corresponds to a drop in the $L E U 2^{\prime \prime}$ 'lacZ expression level of $83 \%$ (Fig. 2B, column 15). The fact that overexpression of three Sir proteins does not repress $100 \%$ may reflect either the limiting dosage of another silencing factor or cell-to-cell variability in expression levels from the plasmid-borne genes. It is noteworthy 

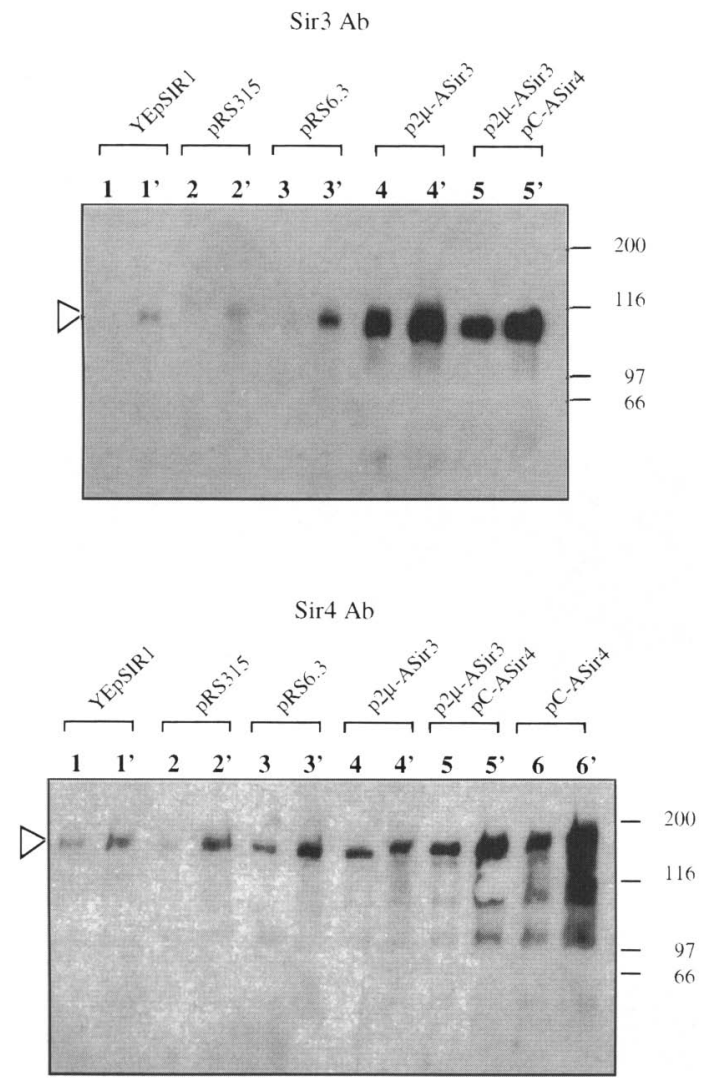

Figure 5. Levels of Sir3 and Sir4 overexpression as determined by Western blot with affinity-purified antibodies. Crude nuclear fractions from EG37 carrying the indicated plasmids and grown in selective media (see Fig. 2; Materials and methods) were analyzed on SDS gels and Western blots by standard techniques. Identical filters were probed with affinity-purified rabbit antibodies against Sir3 (labeled Sir3 Ab), Sir4 (labeled Sir4 Ab), Rap1, and tubulin (data not shown). EG37 carrying the indicated plasmids bear labels of $1-5$, and for each strain the pair of lanes corresponds to proteins from 1 and $2 \mathrm{OD}_{260}$ units of nuclei, respectively. Lanes 6 and $6^{\prime}$ contain the double of this. The open triangles indicate the expected migration of Sir3 and Sir4, and the molecular weight markers are given at the right. Quantitation was performed as described in Materials and methods and shows Sir3 levels to be constant in strains carrying YEpSIR1 (1) and pRS315 (2), 7-fold higher in the presence of pRS6.3 (3), and between 40 - and 50 -fold higher in strains with p $2 \mu-A S i r 3$ (4) or p $2 \mu-A$ Sir3 and pC-ASir4 (5). The Sir4 protein levels are equivalent in strains 1,3 , and 4 and are slightly lower in the presence of the control plasmid pRS315 (lane 2). In the presence of p $2 \mu-$ ASir3 and pC-ASir4 together (5), the level is between 30- and 60 -fold elevated, as it is in the presence of pSIR4-2 $\mu$ alone (lane 6). Compounded error rates gives a $50 \%$ error range for these values.

that the introduction of $\mathrm{pC}-\mathrm{ASir} 4$ and either YEpSIR 1 or pKAN63 (a high-copy-number plasmid with the SIR3 gene under its own promoter) at the same time also compensates for the derepression of $H M L$ conferred by Sir 4 overexpression alone (Fig. 2A, cf. columns 12-14). One explanation of this is that Sir4 forms complexes, probably with Sir3, in which the stoichiometry is carefully balanced. Because Sir protein dosage does not affect the LEU2 promoter in the absence of silencers, we conclude that Sir overexpression reinforces silencer-mediated repression at internal chromosomal locations.

\section{A dispersed localization of Sir3 and Sir4 proteins correlates with silencing at 1ys $2:: \mathrm{HML}:: \mathrm{LEU} 2$ "lacZ}

Using monospecific affinity-purified antibodies for indirect immunofluorescence, we show in Figure 6 that Sir3, Sir4, and Rap1 are highly concentrated in a limited number of foci in the haploid reporter strain EG37 carrying a $L E U 2$ vector with no insert (Fig. 6a,d,g). To demonstrate the specificity of the anti-Sir immunofluorescence, we tested affinity-purified anti-Sir3 on a sir3::LEU2 strain and anti-Sir4 on a sir4::HIS 3 strain, and neither produced staining above background (Fig. 6l, m). Elsewhere, we have shown that these immunoreactive foci coincide in a statistically significant manner with foci detected by in situ hybridization with a highly conserved subtelomeric sequence ( $Y^{\prime}$; Gotta et al. 1996; see also Fig. 6k). In the control strain, Rapl, Sir3, Sir4, and the $Y^{\prime}$ telomeric sequences all produce a very similar pattern of staining: between 4 and 9 discrete foci (green) superimposed on the ethidium bromide stain of genomic DNA /red; Fig. $6 a, d, g, k)$. The specificity of anti-Sir3 and anti-Sir4 for single yeast polypeptides of the appropriate size is demonstrated by Western blot (Fig. 5) and was demonstrated previously for anti-Rap1 (Klein et al. 1992). We then asked the question whether the establishment of silencing at LYS2 owing to overexpression of SIR1, SIR3, and/ or SIR4 reflects the "release" of Sir proteins from this focal localization pattern.

The distribution of Rap1, Sir3, and Sir4 was determined under the conditions of overexpression that allow silencing of the internal lys2::HML::LEU2' lacZ reporter. Overexpression of Sir3 results in a diffuse staining pattern of Sir3 throughout the nucleoplasm (Fig. 6e), consistent with an excess of Sir3 in the foci. Interestingly, in the same cells, the Rapl and Sir4 foci are visible but again are more diffuse (Fig. $6 \mathrm{~b}, \mathrm{~h}$ ). This is shown for a strain carrying pRS6.3, but similar patterns were observed in the presence of $\mathrm{p} 2 \mu$-ASir3 (data not shown). The overexpression of Sir 4 also leads to a diffuse staining of Sir4 (Fig. 6i), a slightly more dispersed Rapl focal staining (Fig. 6c), and a diffuse Sir3 staining superimposed on foci (Fig. 6f). These results clearly show that when either Sir3 or Sir 4 are overproduced, Sir3, Sir4, and, to a lesser extent, Rap 1 are delocalized in a coupled manner. Thus, the restoration of an efficient silencing at internal sites correlates with an increase of available Sir3 and Sir 4 proteins throughout the nucleus. On the other hand, in strains overexpressing Sirl, the focal staining of Rap1, Sir3, and Sir4 is preserved (data not shown). Intriguingly, when both Sir3 and Sir4 are overexpressed, the focal staining pattern for Rap1, Sir3, and Sir4 was partially restored (shown for anti-Sir4; Fig. 6n), indicating that a balanced expression of Sir3 and Sir4 is critical for their localization at telomeric foci. This is consistent 
Figure 6. Sir3 and Sir4 overexpression correlates with a dispersed staining of both Sir proteins. Immunofluorescence was performed as described in Materials and methods with the anti-Sir3 $(d-f)$ and antiSir4 $(g-i, n)$ used on the Western blots in Fig. 5 and with affinity-purified Rapl lpanels a-c). These were visualized by a DTAFcoupled secondary antibody (green signal), whereas the nuclear DNA is counterstained with ethidium bromide (red). Superposition of the two signals is yellow. $(a, d, g)$ EG37 carrying pRS315; $(b, e, h)$ EG37 carrying pRS6.3; $(c, f, i)$ EG37 with pCASir4; (n) EG37 with both pC-ASir4 and p2 $\mu$-ASir3. (I) Anti-Sir3 staining on S1502B carrying a sir3::LEU2 disruption; $(\mathrm{m})$ anti-Sir4 staining on a sir4::HIS3 disruption (JRY341l; see Palladino et al. 1993). (k) In situ hybridization with a 4.8 -kb fragment of the short $\mathrm{Y}^{\prime}$ repeat of $S$. cerevisiae (Louis et al. 1994) visualized by an FITC coupled anti-digoxigenin Fab fragment (Boehringer Mannheim). A diploid wild type for all known loci affecting silencing (GA225; see Palladino et al. 1993) was used for the hybridization. All images are taken as described in Materials and methods. Bar, $1.5 \mu \mathrm{m}$.
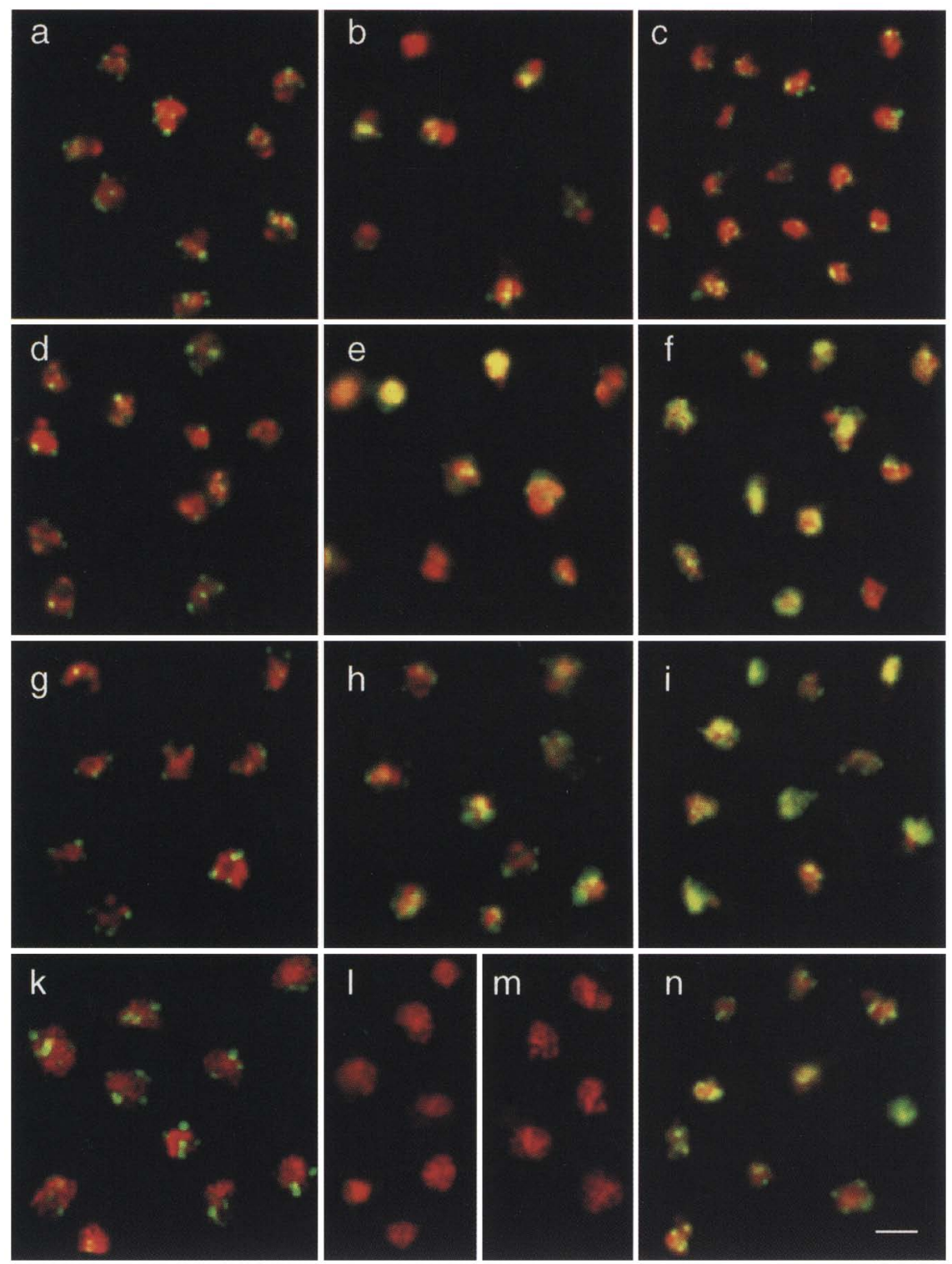

with the hypothesis that Sir3 and Sir4 form complexes of defined stochiometry important for repression (Marshall et al. 1987; Chien et al. 1991; Moretti et al. 1994; Cockell et al. 1995).

\section{Discussion}

\section{Silencer function depends on chromosomal context}

Using a quantitative reporter system for yeast gene repression in which there is no selection for or against expression of the reporter gene, we have shown that the Sir-dependent repression conferred by $H M L$ silencers depends on chromosomal context. That is, a LEU2'lacZ reporter construct flanked by $H M$ silencers is repressed when integrated at $H M L$, at a subtelomeric domain, or if carried on a plasmid. It is not repressed, however, when integrated at LYS2, HIS3, KEX2, and SIN4 that are 342 $\mathrm{kb}, 250 \mathrm{~kb}, 200 \mathrm{~kb}$, and $205 \mathrm{~kb}$, respectively, from the nearest telomeres of chromosomes II (LYS2), XV (HIS3), and XIV (KEX2 and SIN4). Silencing can be restored at the LYS2 internal site by either truncation of the chromosome $13 \mathrm{~kb}$ from the reporter construct or by the insertion of $350 \mathrm{bp}$ of telomeric tract, which is not sufficient to repress transcription on its own (Stavenhagen and Zakian 1994). This requirement for proximity to a telomeric repeat is not promoter nor strain specific, nor is the Sir-dependent repression of this construct simply an extension of telomere repeat-mediated repression.

\section{Sir protein concentration affects internal silencing}

We have demonstrated that Rap1, Sir3, and Sir4 proteins, which play essential roles in telomeric and $H M$ silencing, are not randomly distributed throughout the wild- 
type yeast cell nucleus but localize in four to nine bright foci of staining, as does subtelomeric DNA, detected by in situ hybridization (Palladino et al. 1993; Cockell et al. 1995; Fig. 6). Because we have demonstrated that the majority of the Rapl, Sir3, and Sir4 foci coincide with the FISH signals of the $\mathrm{Y}^{\prime}$ subtelomeric probe /Gotta et al. 1996), we can conclude that in wild-type cells Sir3 and Sir4 are present in high concentrations at their major sites of action, that is, near telomeric repeats.

We argue that this unequal distribution of Sir proteins in the yeast nucleus is responsible for the inability of $H M L$ silencers to repress at LYS2 and other internal loci for the following reasons: First, the elevated expression of silent information regulators Sir1, Sir3, or Sir4, confers repression to a limited degree on the "internal" LEU2' 'lacZ reporter construct. Concomitant overexpression of both Sir3 and Sir 4 or of either in combination with Sirl further improves repression, suggesting that all three proteins are limiting for silencer-mediated repression at internal sites. Coincident with the elevated expression of Sir3 or Sir4, we observe a diffuse staining of both proteins throughout the yeast nucleus, which is consistent with the model that the overexpressed proteins are free to diffuse to the internal lys2::HML::LEU2' lacZ reporter. There may be other yet uncharacterized proteins that are limiting for silencing also released by overexpression of Sir3 or Sir4. Second, we show that the insertion of $350 \mathrm{bp}$ of telomeric tract will allow full repression of the $H M L:: L E U 2^{\prime \prime} l a c Z$ reporter at $L Y S 2$, facilitating the ability of the silencer to function, but not creating a continuum of repression from the telomere. It was shown previously that $\mathrm{TG}_{1-3}$ tracts of a similar length do not alone confer silencing at LYS2, although insertion of an internal tract of $>800$ bp does (Stavenhagen and Zakian 1994). It is assumed that the $\mathrm{TG}_{1-3}$ tracts function by binding Rap1, which in turn, targets Sir3 and Sir4 to the nearby promoter (Moretti et al. 1994). Finally, it has been demonstrated that the artificial targeting of Sir3 or Sir 4 constructs near a reporter gene at internal positions in the chromosome repress the reporter only if the strains carry carboxy-terminally truncated forms of Rapl (Lustig et al. 1996; Marcand et al. 1996). These mutations result in the delocalization of both Sir3 and Sir4 from the telomeric foci (Cockell et al. 1995), which resembles the distribution observed in strains overexpressing SIR3 or SIR4 (Fig. 6). Thus, to repress at internal loci, it appears necessary to achieve a critical local concentration of Sir proteins. This can be achieved either by their release from the telomeric foci, by their overexpression, or through interaction with a sufficient amount of Rapl (or other Sir-binding equivalents) targeted to the reporter gene. The ability to reach this "Sir threshold" is also facilitated by proximity to a chromosomal end. This is depicted schematically in Figure 7.

We show that Sirl is also limiting for silencer-mediated repression and that its overexpression with Sir3 and/ or Sir4 enhances repression of lys2::HML::LEU2' 'lacZ in an additive manner. Intriguingly, the overexpression of Sirl or Sir4 affect differentially the same reporter construct at LYS2 and at $H M L$, decreasing repression at
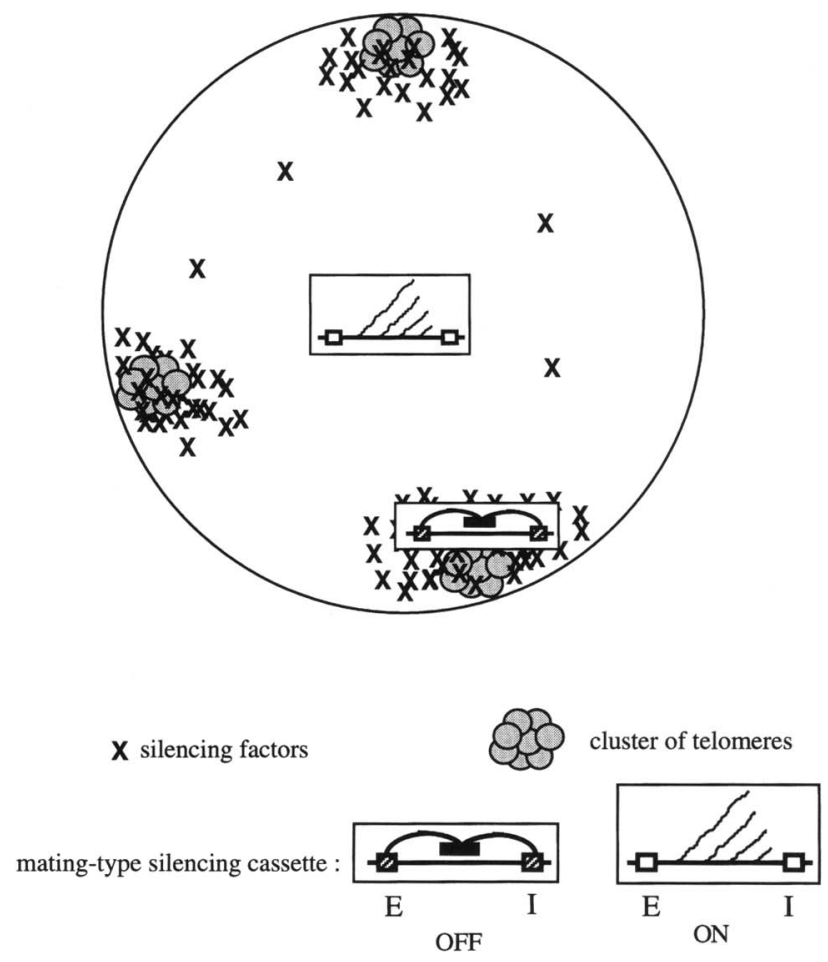

Figure 7. Nuclear subdomains and concentration gradients can affect gene expression. In this model we depict a nucleus with three zones in which silencing factors (e.g., Sir3 and Sir4) are highly concentrated, coinciding with clusters of telomeric repeats. Lower concentrations of Sirs are found throughout the nucleoplasm. We suggest that $H M$ silencer-flanked genes have a better chance to be repressed if they have access to the pool of Sirs at telomeres. To repress at weak or potential silencers that are not subtelomeric, higher concentrations or delocalization of Sir proteins may be required. The "zoning" or indexing of the nucleus is dynamic and should be thought of as concentration gradients in flux, that nonetheless can influence transcription. Indexing may be particularly important for the establishment of inherited patterns of gene expression.

$H M L$ but improving repression at LYS2 (Fig. 2). This may indicate either that an alternative mechanism for silencing functions at internal loci or that the concentration of the factors is different at the two loci, and, therefore, elevated expression provokes opposite effects. The latter explanation is consistent with the available data on Sir4 localization. The subnuclear localization of Sirl is unknown, but it seems unlikely that it will be concentrated at telomeres, because sir1 mutants derepress only at $H M$ loci (Aparicio et al. 1991) and Sirl appears not to bind Rap1 (Chien et al. 1993). Because slight variations in the number of silencers within the nucleus affects $H M$ silencing (Boscheron et al. 1996) and deletion of $H M L$ slightly improves silencing at LYS2, we reason that much of the available Sirl pool may be sequestered at $H M$ loci. Thus, overexpression of Sirl may "free" it, not from telomeric clusters but from association with factors at $H M$ silencers. Additionally, Sirl could help re- 
cruit the limiting concentrations of Sir3 and Sir4 to the LYS2 reporter construct, through interaction with ORC1 that binds both silencer elements (Triolo and Sternglanz 1996).

\section{Physiological implications of unequal Sir distribution}

The immediate physiological consequence of such a compartmentation of silencing factors is to enable bifunctional proteins like Rapl and Abfl, which can mediate both activation and repression of transcription, to have both functions in the same nucleus, depending on their localization with respect to the pools of Sir factors. Because Sir3 and Sir 4 are more concentrated near telomeric sequences, a Rapl molecule in this compartment will be less likely to bind a coactivator like Gcrl (Tornow et al. 1993), which may compete with Sir proteins for the Rapl carboxyl terminus. The opposite is likely to be true at an internal Rapl site. Indication that Sir proteins can compete for the trans-activating potential of the Rapl carboxyl terminus was demonstrated in twohybrid studies using a Rapl-GBD fusion (Moretti et al. 1994).

The bifunctional nature of Rapl-binding sites is particularly important when we consider that our $H M L:: L E U 2^{\prime \prime} l a c Z$ construct is not silent at internal loci, whereas the $H M L \alpha$ cassette can be repressed when integrated far from a telomere (Thompson et al. 1994). Similarly, the introduction of even a single silencer confers partial repression on the MAT $\alpha$ locus (Shei and Broach 1995). The fact that $H M L \alpha$ is less dependent on telomere proximity than our silencer-flanked reporter appears to be attributable to the Rapl site in the $\alpha 2$ promoter, which stimulates $\alpha 2$ transcription in other contexts. We have demonstrated that the insertion of a promoterproximal Rapl site in our HML::LEU2' 'lacZ reporter (Fig. 1B; Boscheron et al. 1996) also improves repression by reinforcing the silencer. Thus, it appears as if $H M$ silencing has evolved a means to reduce dependency on telomere proximity and to improve the stability of repression, through mechanisms like Sirl and additional repressor binding sites.

\section{Are chromosomal domains constrained within the nucleus?}

If local Sir concentrations are too low at LYS2, HIS3, $K E X 2$, and SIN4 to confer silencing, are internal sequences constrained from interacting with this pool of highly concentrated Sir protein near telomeres? In situ hybridization studies with probes specific for LYS2 indicate that the distribution of this region of the chromosome is random with respect to either the nuclear periphery or to Rapl (Gotta et al. 1996). If positioning of sequences in the nucleus is stochastic, then the low level of silencer-mediated repression at LYS2 suggests that the coincidence of LYS2 and telomeres occurs relatively infrequently, at least as compared with $H M L$. On the other hand, the plasmid-borne $H M L:: L E U 2^{\prime \prime} l a c Z$ reporter shows full Sir-dependent repression (Fig. 1B). One expla- nation for this may be that this small extrachromosomal element is able to move more freely within the nucleoplasm than a chromosomal segment and thus might be more efficiently associated with telomere foci and high concentrations of Sir proteins. This implies that although an internal yeast chromosomal segment might not have a strictly defined subnuclear localization, it could nonetheless be constrained from moving freely in the nucleoplasm. Further in situ studies to localize repressed and derepressed domains within the nucleus should shed light on this question.

\section{Nuclear "indexing" and transcription}

In summary, we present evidence that the clustering of telomeric sequences and their attraction for large numbers of Rapl, Sir3, and Sir4 molecules create a subcompartment that favors repression. Unequal distribution of Sir proteins in the nucleus also ensures that Sir complexes are not repressing promiscuously, that is, binding nucleosomes near promoters of genes that use Rapl or Abfl for trans-activation. This compartmentation of the nucleus into different transcriptional states was suggested previously for Drosophila, where genes normally located in either euchromatin or heterochromatin were shown to require their normal chromosomal environment for proper regulation (for review, see Karpen 1994). A clustering of sequences was proposed previously to provide a basis for nuclear indexing, originally based on the idea that AT-rich scaffold attached regions might be brought together in a limited space within the nucleus, providing for a functional nuclear organization by creating zones where polymerases and trans-acting factors are highly concentrated (Gasser and Laemmli 1987). This variation in local concentrations of factors conferred by their cooperative binding to clustered motifs may indeed be a major function for other repeated sequences, such as the centromeric alphoid DNA (Zuckerkandl and Villet 1988).

A disturbance of this distribution phenomenon may result in a modification of the normal transcription pattern, as reported in yeast for a truncated allele of SIR4 (SIR4-42, Kennedy et al. 1995), which was shown to act in a dominant manner to prolong the cell's life span. Because the effect was Sir dependent, a putative "aging" locus was postulated to be repressed by silencing complexes that were mislocalized from the telomeric compartment. The focal staining of Sir3 and Sir4 is disrupted in the SIR4-42 mutant (T. Laroche, M. Gotta, and S.M. Gasser, unpubl.). We predict that the behavior of our internally inserted $H M L$ silencing cassettes mimics cryptic silencers like those postulated for the aging gene.

A further prediction from this model of compartments is that the sequestering of silencing factors is telomere length dependent. In support of this, silencing at $H M R$ is impaired in yeast cells carrying long telomeres (Buck and Shore 1995). Such a mechanism might also be relevant for mammalian cells where telomere shortening appears to act as an antiproliferation signal leading to cellular 
senescence (for review, see Wright and Shay 1995). In this case, decreasing the size of telomeric repeats might liberate factors that are normally telomere bound, to modulate gene expression at other chromatin sites. Two recently described human telomeric proteins /Chong et al. 1995; Bilaud et al. 1996) may play a role similar to that of Rap1, sequestering chromatin-modifying ligands at telomeres. Thus, one can imagine that cellular proliferation control and senescence might indeed reflect the misprogramming of transcription through disturbance of nuclear indices.

\section{Materials and methods}

\section{Plasmids}

Standard molecular biology techniques were performed as described in Sambrook et al. (1989). The LEU2' lacZ silencing cassettes used in this study are derived from plasmids described in Boscheron et al. (1996) that contain a $L E U 2^{\prime \prime}$ lacZ reporter gene flanked by various combinations of $H M L$-E and $H M L-\mathrm{I}$ alleles. $\mathrm{E}$ indicates the wild-type $H M L$-E sequence, $\mathbf{e}_{\mathbf{1}}$ indicates a 43-nucleotide deletion of $\mathbf{E}$, $\mathbf{I}$ indicates the wild-type sequence of $H M L$-I, and $\mathbf{i}$ indicates a complete deletion of $\mathbf{I}$. The different cassettes are named according to the allele combination and with the symbol $>$ or $<$ indicating the orientation of the reporter gene; for example, $\mathbf{E}>\mathbf{I}$ corresponds to the reporter gene flanked by the two wild-type silencers with the LEU2 promoter adjacent to $H M L$-E, and so on. $\mathbf{E} \in<$ I carries wild-type silencers with an additional Rapl-binding site ( $\epsilon$ sequence) adjacent to $H M L$-E and downstream of the $L E U:: l a c Z$ reporter. To facilitate usage in the text, insertion of the LEU2'lacZ reporter flanked by functional silencers at $H M L$ will be indicated as $H M L:: L E U 2^{\prime \prime} l a c Z$ and nonfunctional silencers will be indicated as $h m l:: L E U 2^{\prime \prime} l a c Z$.

pLYS2URA is a derivative of pDP6 (Fleig et al. 1986) in which a $2.3-\mathrm{kb}$ HindIII fragment from pelURA3 $\mathrm{I}^{\mathrm{AB}}$, containing $U R A 3$ flanked by sequences derived from $H M L-E$ and $H M L-I \mid \mathbf{e}_{\mathbf{1}}$ and $\mathbf{I}^{\mathbf{B B}}$ alleles, respectively; Boscheron et al. 1996), was inserted at $X$ hoI. To integrate a $L E U 2^{\prime \prime} l a c Z$ reporter gene flanked by $H M L$-E and $H M L$-I at the HIS3 locus, a 5.2-kb HindIII fragment from $\mathrm{pE}>\mathrm{I}$ was inserted into the EcoRV-NotI sites of the integrative plasmid pRS303, leading to pHIS3E $>$ I. To integrate a LEU2' 'lacZ reporter gene flanked by $H M L$-E and $H M L$-I at the KEX2 locus (respectively SIN4), a $1.8-\mathrm{kb}$ XhoI DNA fragment spanning the KEX2 stop codon (respectively SIN4) was inserted at the XhoI site of pHIS3E>I, such that the KEX2 stop codon (respectively $S I N 4$ ) is located 450 nucleotides (respectively 1.4 $\mathrm{kb}$ from the $H M L$-E insert. The resulting plasmid was named pKEX2E $>$ I (respectively pSIN4E $>$ I). The primers used to amplify by PCR the KEX2 1.8 -kb fragment are $5^{\prime}$-TATTCACTCGAGTGATATCAACGGCAGATGC and 5'-GCCCATATCATGCTCGAGATCACCGCAGAC; those used to amplify the SIN4 1.8-kb fragment are 5'-TCCATCGCTCGAGTGGATGAAGGTTTCACC and 5'-TTTCACTTCTCGAGGAATGATCATGAGAGCC. An XhoI restriction site was placed in each primer for convenient cloning (underlined). $\mathrm{pC}-\mathrm{E}>\mathrm{I}$, a LEU2-

Table 1. Yeast strains used in this study

\begin{tabular}{|c|c|c|}
\hline Strain & Genotype & Source \\
\hline $\mathrm{S} 150-2 \mathrm{~B}$ & MATa leu2-3,112 ura3-52 trp1-289 his3 gal2 & a gift from $\mathrm{J}$. Broach (Princeton University, NJ) \\
\hline W303-1B & Mato ura3-1 trp1-1 ade2-1 leu2-3,112 his3-11,15 & $\begin{array}{l}\text { a gift from R. Rothstein (Columbia University, } \\
\text { New York, NY) }\end{array}$ \\
\hline EG5 & S150-2B $H M L:: \mathrm{E}>\mathrm{I}(\mathrm{pRS} 315)$ & Boscheron et al. (1996) \\
\hline EG28 & EG5 $\operatorname{sir} 3:: T R P 1_{1}$ & Boscheron et al. (1996) \\
\hline EG35 & $\mathrm{S} 150-2 \mathrm{~B}$ lys2::el-URA3-I $\mathrm{I}^{\Delta \mathrm{B}}$ & this study \\
\hline EG36 & S150-2B lys2:: $\mathrm{e}_{1}>\mathrm{I}(\mathrm{pRS} 315)$ & this study \\
\hline EG37 & $\mathrm{S} 150-2 \mathrm{~B} H M L:: \mathrm{E}>\mathrm{I}$ & this study \\
\hline EG47 & EG5 P78::URA3 & this study \\
\hline EG59 & S150-2B lys2::E > I (pRS315) & this study \\
\hline EG70 & S150-2B lys2::E > I & this study \\
\hline EG82 & S150-2B lys2::E $\epsilon<\mathrm{I}(\mathrm{pRS} 315)$ & this study \\
\hline EG84 & EG5 X W303-1B & this study \\
\hline EG85 & EG59 X W303-1B & this study \\
\hline EG86 & EG85 LYS2-GRS1/lys2::E > I-GRS1::URA3-TEL & this study \\
\hline EG87 & EG85 LYS2-GRS1::URA3-TEL/lys2::E > I-GRS1 & this study \\
\hline EG90 & EG59 hml::URA3 & this study \\
\hline EG93 & EG5 adh4::URA3-TEL & this study \\
\hline EG108 & EG59 sir3::TRP1 & this study \\
\hline EG109 & EG37 sir1::LEU2 & Boscheron et al. (1996) \\
\hline EG111 & EG70 sir1::LEU2 & this study \\
\hline EG112 & S150-2B HIS3::E > I (pRS315) & this study \\
\hline EG139 & EG37 sir4::HIS3 (pAAH5) & this study \\
\hline EG162 & EG70 sir4::HIS3 (pAAH5) & this study \\
\hline GA210 & 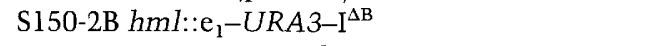 & Boscheron et al. $(1996)$ \\
\hline LM1 & EG59 GRS1::URA3-Tel350 & this study \\
\hline $\mathrm{LM} 2$ & S150-2B KEX2::E > I (pRS315) & this study \\
\hline LM3 & S150-2B SIN4::E > I (pRS315) & this study \\
\hline $\mathrm{Z2}$ & $\mathrm{S} 150-2 \mathrm{~B}(\mathrm{pC}-\mathrm{E}>\mathrm{I})$ & this study \\
\hline $\mathrm{Z} 11$ & $\mathrm{~S} 150-2 \mathrm{~B}\langle\mathrm{pC}-\mathrm{e}>\mathrm{i}\rangle$ & this study \\
\hline
\end{tabular}


CEN-ARS plasmid, carries the 5.4-kb $X b a I-H i n d I I I$ fragment from $\mathrm{pE}>\mathrm{I}$ inserted between the $\mathrm{XbaI}$ and HindIII sites of pRS315 (Sikorski and Hieter 1989). pC-e $>i$ is similar to pC-E $>$ I except that it carries the $5-\mathrm{kb} \mathrm{XbaI}-\mathrm{Hind}$ III fragment from $\mathrm{pe}_{1}>\mathrm{i}$.

For disrupting the $H M L$ locus, we constructed pelURAi that contains a KpnI URA3 fragment inserted at the KpnI site of a plasmid DNA carrying null alleles of both $H M L$ silencers $\left(\mathbf{e}_{\mathbf{1}}\right.$ and i) with the URA3 promoter located adjacent to i. Plasmid pURATel80LYS derived from pVII-L URA3-TEL (Gottschling et al. 1990 ) by replacing the $A D H 4$ fragment by a l-kb SallHindIII GRS1 fragment, such that the SalI site was positioned away from URA3. The primers used to amplify by PCR the GRS1 fragment are 5'-TTGATGACATTGTCGACGGAACCTCTAACTTGCTTGG and 5'-TGATGGCAGAGATTGAACATTTCGTTGACCC. A SalI restriction site was placed at the end of one primer for convenient cloning (underlined). The HindIII cloning site was provided by an internal site present in the PCR-generated fragment that is positioned 11404 nucleotides away from the XhoI site within LYS2 that was used for inserting the reporter silencing cassettes. Plasmid pURATel350LYS derived from pURATel80LYS by replacing the $1.1-\mathrm{kb} B a m \mathrm{HI}-$ HindIII fragment by a BamHI-HindIII fragment of pYTel, carrying the URA3 gene and 270 nucleotides of yeast telomeric repeats in pUC19.

To integrate the URA3 gene into the left subtelomeric region of chromosome III, we replaced an internal 2408-nucleotide KpnI fragment from p78 (kindly provided by C. Newlon, New Jersey Medical School, Newark), a derivative of YIp5 that contains a 4530-nucleotide EcoRI fragment located $2 \mathrm{~kb}$ from the left telomere of chromosome III, by a $1-\mathrm{kb} K p n I$ URA3 fragment. The resulting plasmid is named p78URA.

p $2 \mu-A$ Sir3 was obtained by cloning a 3.7-kb HpaI fragment carrying SIR3 excised from pRS6.3 (SIR3 in pSEYC58, a gift from J. Rine, University of California, Berkeley) into the HindIII site of pAAH5, a $2 \mu$ plasmid carrying the $A D C 1$ promoter upstream of a cloning HindIII site and the $3^{\prime} A D C 1$ region downstream of this site. pC-ASir4 is a URA3-CEN-ARS plasmid containing the Xbal-SalI SIR4-containing fragment from pADH-SIR4 (Cockell et al. 1995) cloned between the XbaI and Sall sites of pRS316 (Sikorski and Hieter 1989).

\section{Yeast strain constructions}

Yeast media and methods were as described in Rose et al. (1990). The strains used in this study are described in Table 1. $\beta$-galactosidase assays on permeabilized yeast cells were performed as described in Boscheron et al. (1996). The targeted integration of the LEU2"lacZ silencing reporter cassette at the LYS2 locus was done in two steps (Boscheron et al. 1996). First, pLYS2URA cut with BamHI and NruI, generating terminal sequences homologous to the LYS2 locus, was transformed into S150-2B producing EG35. Insertions were checked by a Southern blot analysis. Second, an $X b a I-N o t I$ fragment from the plasmids carrying the LEU2" 'lacZ reporter gene was used to replace the URA3 gene by cotransformation with pRS315. The Leu ${ }^{+}$transformants were replica-plated to $\mathrm{SD}$-uracil, $\mathrm{SD}+$ uracil, and $\mathrm{SD}+$ uracil + 5-FOA. The Ura ${ }^{-}, 5-\mathrm{FOA}^{\mathrm{R}}$ colonies were analyzed both by Southern blot analysis and by PCR. The mutant or wild-type $\mathbf{E}$ and I silencer alleles were checked by the presence of a BglII site in the case of $\mathbf{e}_{\mathbf{1}}$ (or absence for $\mathbf{E}$ ) and by an EcoRV site in the case of $\mathbf{I}^{\mathbf{A B}}$ (or its absence at $\mathbf{I}$ ). Insertion of the additional Rapl site (the $\epsilon$ oligonucleotide) is described in Boscheron et al. (1996).

The integration of pHIS3E $>\mathrm{I}$ into the his 3 locus was performed by transforming PstI-linearized plasmid DNA into S150-
$2 \mathrm{~B}$, selecting $\mathrm{His}^{+}$cells and screening the correct integration events by a Southern restriction site analysis, producing EG112. The integration of pURATel350LYS into the GRS1 locus was performed by transforming BgIII-linearized plasmid DNA into EG59, selecting $\mathrm{Ura}^{+}$cells, and screening the correct integration events by PCR and Southern restriction site analysis. The resulting strain is called LM1. The integration of pKEX2E $>I$ into the $3^{\prime}$ region of the KEX2 locus was performed by transforming BsrGI-linearized plasmid DNA into S150-2B, selecting $\mathrm{His}^{+}$cells, and screening the correct integration events by Southern restriction analysis. The resulting strain is LM2. An identical process was performed for integration of pSIN4E $>$ I, linearized with Tth111I, at SIN4, producing LM3.

The fragmentation of the $A D H 4$-distal part of chromosome VII in strain EG5 with pVII-L URA3-TEL was performed as described in Gottschling et al. (1990), leading to EG93. For the fragmentation of the GRS1-distal part of chromosome II, pURATel80LYS DNA cut with EcoRI and Sall was transfected into the diploid strain EG85, selecting Ura ${ }^{+}$cells. The fragmentation of either homolog was analyzed by a Southern restriction site analysis by running the agarose gel on a FIGE mapper apparatus (Bio-Rad). MluI digestion of the fragmented chromosome II carrying the $L E U 2^{\prime}$ "lacZ silencing cassette inserted at LYS2 released a terminal $15.3-\mathrm{kb}$ fragment, visualized by Southern hybridization and sensitive to a BAL 31 digestion (data not shown). The resulting strain was named EG86. The fragmented chromosome II with a wild-type LYS2 region produces a $18.4-\mathrm{kb}$ fragment, sensitive to BAL 31 digestion but not detectable with a lacZ probe, in a strain named EG87.

The $\operatorname{sir} 1$ and $\operatorname{sir} 3$ disruption cassette is described in Boscheron et al. (1996), the sir4 gene disruption used pIR276 (Kimmerly and Rine 1987), and disruption of $H M L$ was done with a linear fragment from pelURAi (see Materials and methods, Plasmids) containing the URA3 gene flanked by $H M L$ silencer null alleles using one-step gene replacement.

For overexpressing Sirl, Sir3, and/or Sir4, we transformed the appropriate strains with the high-copy plasmid YEpSIRI (Stone et al. 1991), with the CEN-ARS plasmid pRS6.3 (see above), with the high-copy plasmid p $2 \mu$-ASir 3 expressing Sir 3 from an $A D C 1$ promoter (see above), with the high-copy plasmid pKAN63 (Ivy et al. 1986), and with either pC-ASir4, which is a CEN-ARS plasmid expressing Sir4 from an $A D C 1$ promoter, or from the high-copy plasmid pFP320, which carries a BgIII-EcoRI fragment containing SIR4 cloned in pRS424, a TRP1-2 $\mu$ vector (a gift from F. Palladino, ISREC, Lausanne, Switzerland).

\section{Immunofluorescence, in situ hybridization,} and Western blots

Haploid strains carrying the indicated plasmids were precultured and grown overnight in selective media. Cells were treated for $10 \mathrm{~min}$ at $30^{\circ} \mathrm{C}$ with $1000 \mathrm{U} / \mathrm{ml}$ of lyticase (Verdier et al. 1990) in growth media containing $1.2 \mathrm{M}$ Sorbitol to partially digest the cell wall, after which cells were washed and fixed with formaldehyde (Palladino et al. 1993) and reacted with affinity-purified anti-Rapl (Klein et al. 1992), anti-Sir3, or antiSir4 antibodies (Gotta et al. 1996). Secondary antibodies conjugated to DTAF were preadsorbed against fixed spheroplasts prior to use. In situ hybridization was performed on cells prepared identically to those for immunofluorescence, using a short $\mathrm{Y}^{\prime}$ probe described in Louis et al. (1994). The probe was nick-translated using digoxigenin-derivatized dUTP (Boehringer Mannheim/ and detected with FITC-coupled sheep anti-digoxigenin Fab fragments (Boehringer Mannheim) as described (Gotta et al. 1996). DNA was detected by EtBr staining $(1 \mu \mathrm{g} / \mathrm{ml}$ ) in the mounting solution [ $1 \times$ PBS, $50 \%$ glycerol, $24 \mu \mathrm{g} / \mathrm{ml} \mathrm{l,4}$ 
diazabicyclo-2,2,2,octane (DABCO)]. Confocal microscopy was performed on a Zeiss Axiovert 100 microscope (Zeiss Laser Scanning Microscope 410 system) with a $63 \times$ Plan-Apochromat objective ( 1.4 oil). Standardized conditions were used for image scanning, averaging, and processing, such that all treatments of images were done in parallel and identically for all images shown.

Western blots were performed on proteins from crude nuclear preparation (Verdier et al. 1990) from the indicated strains. In sequential lanes 1 and $2, \mathrm{OD}_{260}$ units of each nuclear preparation denatured in $2 \%$ SDS and sonicated to fragment DNA were loaded per slot, as indicated, and transferred to nitrocellulose by standard procedures. The same affinity-purified antibodies used in the immunofluorescence were used to probe the filter, and the primary antibodies were detected with a peroxidase-coupled secondary antibody. The peroxidase signal was detected using ECL chemiluminescence on preflashed film (Amersham, UK). Quantitation was done by scanning three exposures of the autoradiograph with a CCD camera and quantifying the images with the PhosphorImager, and correction for loading equality was achieved by standardization to the anti-tubulin and total Coomassie blue signals. For every sample at least one of the two lanes was consistently in the linear response curve of the luminescence reaction.

\section{Acknowledgments}

We are grateful to J. Broach, D. Gottschling, F. Palladino, L. Pillus, J. Rine, and D. Shore for gifts of plasmids, A. Formenton and $M$. Roberge for antibodies prepared in the Gasser laboratory, E. Revardel for strain constructions (EG84 and EG85), and T. Laroche for excellent technical help. M.G. thanks ISREC for a Ph.D. fellowship; E.G. thanks the European Molecular Biology Organization for his long-term fellowship at ISREC where this work was initiated. This work was supported by grants from the Swiss National Science Foundation and the Human Frontiers Research Program (to S.M.G.) and by Association pour la Recherche sur le Cancer (ARC), Groupement de Recherches et d'Etudes sur les Génomes (GREG), Ligue Nationale contre le Cancer, Région Rhône-Alpes, and Association Française de lutte contre la Mucovisidose (AFLM) (to E.G.).

The publication costs of this article were defrayed in part by payment of page charges. This article must therefore be hereby marked "advertisement" in accordance with 18 USC section 1734 solely to indicate this fact.

\section{References}

Aparicio, O.M., B.L. Billington, and D.E. Gottschling. 1991. Modifiers of position effect are shared between telomeric and silent mating-type loci in S. cerevisiae. Cell 66: 12791287.

Bell, S.P., R. Kobayashi, and B. Stillman. 1993. Yeast Origin Recognition Complex functions in transcription silencing and DNA replication. Science 262: 1844-1848.

Bilaud, T., C.E. Koering, E. Binet-Brasselet, K. Anselin, A. Pollice, S.M. Gasser, and E. Gilson. 1996. The Telobox, a Mybrelated telomeric DNA binding motif found in proteins from yeast, plants and human. Nucleic Acids Res. 24: 1294-1303.

Boscheron, C., L. Maillet, S. Marcand, M. Tsai-Pflugfelder, S.M. Gasser, and E. Gilson. 1996. Cooperation at a distance between silencers and proto-silencers at the yeast $H M L$ locus. EMBO J. 15: 2184-2195.

Brand, A.H., L. Breeden, J. Abraham, R. Sternglanz, and K.
Nasmyth. 1985. Characterization of a "Silencer" in yeast: A DNA sequence with properties opposite to those of a transcriptional enhancer. Cell 41: 41-48.

Brand, A.H., G. Micklem, and K. Nasmyth. 1987. A yeast silencer contains sequences that can promote autonomous plasmid replication and transcriptional activation. Cell 51: 709-719.

Buchman, A.R., W.J. Kimmerly, J. Rine, and R.D. Kornberg. 1988. Two DNA-binding factors recognize specific sequences at silencers, upstream activating sequences, autonomously replicating sequences and telomeres in $S$. cerevisiae. Mol. Cell. Biol. 8: 210-225.

Buck, S.W. and D. Shore. 1995. Action of a RAP1 carboxy-terminal silencing domain reveals an underlying competition between $H M R$ and telomeres in yeast. Genes \& Dev. 9: 370384.

Butner, K. and C.W. Lo. 1986. Modulation of tk expression in mouse pericentromeric heterochromatin. Mol. Cell. Biol. 6: 4440-4449.

Carlson, M., J.L. Celenza, and F.J. Eng. 1985. Evolution of the dispersed SUC gene family of $S$. cerevisiae by rearrangements of chromosome telomeres. Mol. Cell. Biol. 5: 2894 2902.

Chien, C., P.L. Bartel, R. Strernglanz, and S. Fields. 1991. The two-hybrid system: A method to identify and clone genes for proteins that interact with a protein of interest. Proc. Natl. Acad. Sci. 88: 9578-9582.

Chien, C., S. Buck, R. Sternglanz, and D. Shore. 1993. Targeting of SIR1 protein establishes transcriptional silencing at $H M$ loci and telomeres in yeast. Cell 75: 531-541.

Chong, L., B. van Steensel, D. Broccoli, L. Erdjument-Bromage, J. Hanish, P. Tempst, and T. de Lange. 1995. A human telomeric protein. Science 270: 1663-1667.

Cockell, M., F. Palladino, T. Laroche, G. Kyrion, C. Liu, A.J. Lustig, and S.M. Gasser. 1995. The C-termini of Sir4 and Rapl affect Sir3 localization in yeast cells: Evidence for a multicomponent complex required for telomeric silencing. $\%$. Cell Biol. 129: 909-924.

Cremer, T.A., R. Kurz, S. Zirbel, B. Dietzel, E. Rinke, M.R. Schröck, U. Speicher, A. Mathieu, P. Jauch, H. Emmerich, T. Sherthan, C. Ried, C. Cremer, and P. Lichter. 1993. The role of chromosome territories in the functional compartmentalization of the cell nucleus. Cold Spring Harbor Symp. Quant. Biol. 58: 777-792.

Diller, J.D. and M.K. Raghuraman. 1994. Eukaryotic replication origins: Control in space and time. Trends Biochem. Sci. 19: $320-325$

Ferguson, B.M. and W.L. Fangman. 1992. A position effect on the timing of replication origin replication in yeast. Cell 68: 333-339.

Fleig, U.N., R.D. Pridmore, and P. Philippsen. 1986. Construction of LYS2 cartridges for use in genetic manipulations of Saccharomyces cerevisiae. Gene 46: 237-245.

Funabiki, H., I. Hagan, S. Uzawa, and M. Yanagida. 1993. Cell cycle-dependent specific positioning and clustering of centromeres and telomeres in fission yeast. I. Cell Biol. 121: 961-976.

Gasser, S.M. and U.K. Laemmli. 1987. A glimpse at chromosomal order. Trends Genet. 3: 16-22.

Gilson, E. and S.M. Gasser. 1995. Repressor Activator Protein 1 and its ligands: Organising chromatin domains. Nucleic Acids Mol. Biol. 9: 308-327.

Gilson, E., T. Laroche, and S.M. Gasser. 1993. Telomeres and the functional architecture of the nucleus. Trends Cell Biol. 3: 128-134.

Gotta, M., T. Laroche, A. Formenton, L. Maillet, H. Shertan, and 
S.M. Gasser. 1996. Cytological evidence for the clustering of telomeres and their colocalization with Rap1, Sir3 and Sir4 proteins in wild-type $S$. cerevisiae. J. Cell Biol. (in press).

Gottschling, D.E., O.M. Aparicio, B.L. Billington, and V.A. Zakian. 1990. Position effect at $S$. cerevisiae telomeres: Reversible represssion of Pol II transcription. Cell 63: 751762.

Hecht, A., T. Laroche, S. Strahl-Bolsinger, S.M. Gasser, and M. Grunstein. 1995. Histone $\mathrm{H} 3$ and $\mathrm{H} 4 \mathrm{~N}$ termini interact with the Silent Information Regulators Sir 3 and Sir4 in vitro: A molecular model for the formation of heterochromatin in yeast. Cell 80: 583-592.

Heitz, E. 1934. Uber $\alpha$ und $\beta$ Heterochromatin, sowie Konstanz und Bau der Chromomeren bei Drosophila. Biol. Zentralblatt 45: 588-609.

Ivy, J.M., A.J.S. Klar, and J.B. Hicks. 1986. Cloning and characterization of four SIR genes of S. cerevisiae. Mol. Cell. Biol. 6: $688-702$.

Karpen, G.H. 1994. Position-effect variegation and the new biology of heterochromatin. Curr. Opin. Gen. Dev. 4: 281291.

Kennedy, B.K., N.R. Austriaco, J. Zhang, and L. Guarente. 1995. Mutation in the Silencing gene SIR4 can delay aging in $S$. cerevisiae. Cell 80: 485-496.

Kimmerly, W. and J. Rine. 1987. Replication and segregation of plasmids containing cis-acting regulatory sites of silent mating type genes in $S$. cerevisiae are controlled by the SIR genes. Mol. Cell. Biol. 7: 4225-4237.

Klar, A.J.S., J.N. Strathern, J.R. Broach, and J.B. Hicks. 1981. Regulation of transcription in expressed and unexpressed mating type cassettes of yeast. Nature 289: 239-244.

Klein, F., T. Laroche, M.E. Cardenas, J.F.X. Hofmann, D. Schweizer, and S. M. Gasser. 1992. Localization of RAPl and topoisomerase II in nuclei and meiotic chromosomes of yeast. I. Cell Biol. 117: 935-948.

Kyrion, G., C. Liu, and A.J. Lustig. 1993. RAP1 and telomere structure regulate telomere position effects in Saccharomyces cerevisiae. Genes \& Dev. 7: 1146-1159.

Laurenson, P. and J. Rine. 1992. Silencers, silencing and heritable transcriptional states. Microbiol. Rev. 56: 543-560.

Liu, C., X. Mao, and A.J. Lustig. 1994. Mutational analysis defines a C-terminal tail domain of RAPl essential for telomeric silencing in S. cerevisiae. Genetics 138: 1025-1040.

Louis, E.J., E.S. Naumova, A. Lee, G. Naumov, and J.E. Haber. 1994. The chromosome end in yeast: Its mosaic nature and influence on recombination dynamics. Genetics 136: 789802.

Lustig, A.J., C. Liu, C. Zhang, and J.P. Hanish. 1996. Tethered Sir3p nucleates silencing at telomeres and internal loci in Saccharomyces cerevisiae. Mol. Cell. Biol. 16: 2483-2495.

Mahoney, D.J. and J. Broach. 1989. The $H M L$ mating type cassette of $S$. cerevisiae is regulated by two functionally equivalent silencers. Mol. Cell. Biol. 9: 4621-4630.

Mahoney, D.J., R. Marquardt, G.J. Shei, A.B. Rose, and J.R. Broach. 1991. Mutations in the HML-E silencer of Saccharomyces cerevisiae yield metastable inheritance of transcriptional repression. Genes \& Dev. 5: 605-615.

Marcand, S., S.W. Buck, P. Moretti, E. Gilson, and D. Shore. 1996. Silencing of genes at nontelomeric sites in yeast is controlled by sequestration of silencing factors at telomeres by Rapl protein. Genes \& Dev. 10: 1297-1309.

Marshall, M., D. Mahoney, A. Rose, J.B. Hicks, and J.R. Broach. 1987. Functional domains of SIR4, a gene required for position effect regulation in Saccharomyces cerevisiae. Mol. Cell. Biol. 7: 4441-4452.

Mathog, D., M. Hochstrasser, Y. Gruenbaum, H. Saumweber, and J. Sedat. 1984. Characteristic folding pattern of polytene chromosomes in Drosophila salivary gland nuclei. Nature 308: 414-421.

McNally, F.J. and J. Rine. 1991. A synthetic silencer mediates SIR-dependent functions in Saccharomyces cerevisiae. Mol. Cell. Biol. 11: 5648-5659.

Micklem, G., A. Rowley, J. Harwood, K. Nasmyth, and J.F.X. Diffley. 1993. Yeast origin recognition complex is involved in DNA replication and transcriptional silencing. Nature 366: 87-89.

Moretti, P., K. Freeman, L. Coodly, and D. Shore. 1994. Evidence that a complex of SIR proteins interacts with the silencer and telomere binding protein RAP1. Genes \& Dev. 8: $2257-2269$.

Nasmyth, K.A., K. Tatchell, B.D. Hall, C. Astell, and M. Smith. 1981. A position effect in the control of transcription at yeast mating type loci. Nature 289: 244-250.

Palladino, F. and S.M. Gasser. 1994. Telomere maintenance and gene repression: A common end? Curr. Opin. Cell Biol. 6: 373-380.

Palladino, F., T. Laroche, E. Gilson, A. Axelrod, L. Pillus, and S.M. Gasser. 1993. SIR3 and SIR4 proteins are required for the positioning and integrity of yeast telomeres. Cell 75: 543-555.

Paro, R. 1993. Mechanisms of heritable gene repression during development of Drosophila. Curr. Opin. Cell Biol. 5: 9991005.

Pillus, L. and J. Rine. 1989. Epigenetic inheritance of transcriptional states in S. cerevisiae. Cell 59: 637-647.

Rae, P.M.M. and W.W. Franke. 1972. The interphase distribution of satellite DNA-containing heterochromatin in mouse nuclei. Chromosoma 39: 443-456.

Renauld, H., O.M. Aparicio, P.D. Zierath, B.L. Billington, S.K. Chhablani, and D.E. Gottschling. 1993. Silent domains are assembled continuously from the telomere and are defined by promoter distance and strength, and by SIR 3 dosage. Genes \& Dev. 7: 1133-1145.

Rose, M.D., F. Winston, and P. Hieter. 1990. Methods in yeast genetics. Cold Spring Harbor Laboratory Press, Cold Spring Harbor, NY.

Sambrook, J., E.F. Fritsh, and T. Maniatis. 1989. Molecular cloning: A laboratory manual. Cold Spring Harbor Laboratory Press, Cold Spring Harbor, NY.

Shei, G.J. and J.R. Broach. 1995. Yeast silencers can act as orientation-dependent gene inactivation centers that respond to environmental signals. Mol. Cell. Biol. 15: 34963506.

Shore, D. and K. Nasmyth. 1987. Purification and cloning of a DNA binding protein from yeast that binds to both silencer and activator elements. Cell 51: 727-732.

Sikorski, R.S. and P. Hieter. 1989. A system of shuttle vectors and yeast host strains designed for efficient manipulation of DNA in S. cerevisiae. Genetics 122: 19-27.

Singer, M.S. and D.E. Gottschling. 1994. TLC1: Template RNA component of Saccharomyces cerevisiae telomerase. Science 266: $404-409$.

Stavenhagen, J.B. and V.A. Zakian. 1994. Internal tracts of telomeric DNA act as silencers in Saccharomyces cerevisiae. Genes \& Dev. 8: 1411-1422.

Stone, E.M., M.J. Swanson, A.M. Romeo, J.B. Hicks, and R. Sternglanz. 1991. The SIR1 gene of Saccharomyces cerevisiae and its role as an extragenic suppressor of several mating-defective mutants. Mol. Cell. Biol. 11: 2253-2262.

Sussel, L. and D. Shore. 1991. Separation of transcriptional activation and silencing functions of the RAP1-encoded repressor/activator protein 1 : Isolation of viable mutants affecting 
both silencing and telomere length. Proc. Natl. Acad. Sci. 88: $7749-7753$.

Thompson, J.S., L.M. Johnson, and M. Grunstein. 1994. Specific repression of the yeast silent mating type locus $H M R$ by an adjacent telomere. Mol. Cell. Biol. 14: 446-455.

Tornow, J., X. Zeng, W. Gao, and G.M. Santangelo. 1993. GCR1, a transcriptional activator in $S$. cerevisiae, complexes with $\mathrm{RAPl}$ and can function without its DNA binding domain. EMBO I. 12: 2431-2437.

Triolo, T. and R. Sternglanz. 1996. Role of interactions between the origin recognition complex and SIR 1 in transcriptional silencing. Nature 381: 251-253.

Verdier, J.M., M. Stalder, M. Roberge, B. Amati, A. Sentenac, and S.M. Gasser. 1990. Preparation and characterization of yeast nuclear extracts for efficient RNA polymerase B (II)dependent transcription in vitro. Nucleic Acids Res. 18: 7033-7039.

Vourc'h, C., D. Taruscio, A.L. Boyle, and D.C. Ward. 1993. Cell cycle-dependent distribution of telomeres, centromeres, and chromosome-specific subsatellite domains in the interphase nucleus of mouse lymphocytes. Exp. Cell Res. 205: 142-151.

Wright, W.E. and J.W. Shay. 1995. Time, telomeres and tumours: Is cellular senescence more than an anticancer mechanism? Trends Cell Biol. 5: 293-297.

Zuckerkandl, E. and R. Villet. 1988. Generation of high specificity of effect through low-specificity binding of proteins to DNA. FEBS Lett. 231: 291-298. 


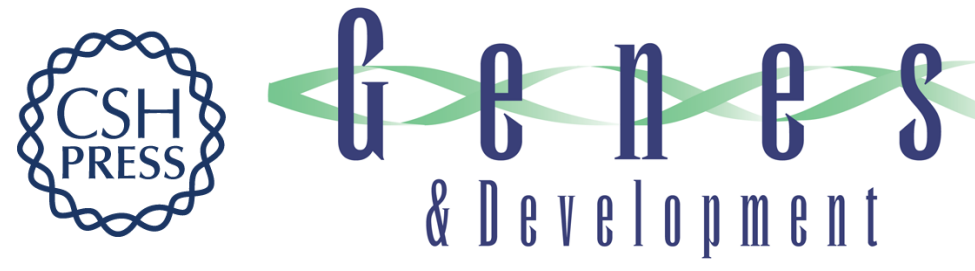

\section{Evidence for silencing compartments within the yeast nucleus: a role for telomere proximity and Sir protein concentration in silencer-mediated repression.}

L Maillet, C Boscheron, M Gotta, et al.

Genes Dev. 1996, 10:

Access the most recent version at doi:10.1101/gad.10.14.1796

References This article cites 65 articles, 31 of which can be accessed free at:

http://genesdev.cshlp.org/content/10/14/1796.full.html\#ref-list-1

License

Email Alerting

Service

Receive free email alerts when new articles cite this article - sign up in the box at the top right corner of the article or click here.

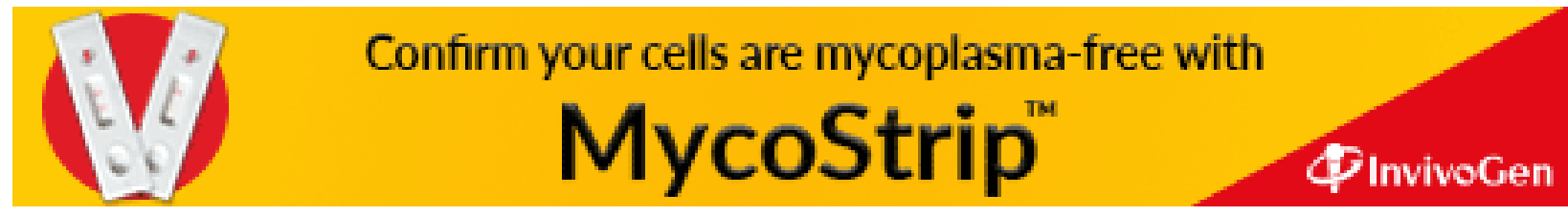

